\title{
The neural dynamics of stimulus and response conflict processing as a function of response complexity and task demands
} \author{
Marty G. Woldorff a,b,c,d,e,f \\ a Center for Cognitive Neuroscience, Duke University, Durham, North Carolina, USA \\ b Department of Neurobiology, Duke University, Durham, North Carolina, USA \\ ${ }^{\mathrm{c}}$ Department of Neurology, Otto-von-Guericke University Magdeburg, Magdeburg, Germany \\ d Leibniz Institute for Neurobiology, Magdeburg, Germany \\ e Department of Psychiatry and Behavioral Sciences, Duke University, Durham, North Carolina, USA \\ ${ }^{\mathrm{f}}$ Department of Psychology and Neuroscience, Duke University, Durham, North Carolina, USA
}

Sarah E. Donohue a,b,c,d,*, Lawrence G. Appelbaum ${ }^{\mathrm{e}}$, Cameron C. McKay ${ }^{\mathrm{a}}$,

\section{A R T I C L E I N F O}

\section{Article history:}

Received 29 October 2015

Received in revised form

26 January 2016

Accepted 28 January 2016

Available online 28 January 2016

\section{Keywords:}

Conflict

Stroop

Flanker

EEG

N2

N450

LPC

LRP

\begin{abstract}
A B S T R A C T
Both stimulus and response conflict can disrupt behavior by slowing response times and decreasing accuracy. Although several neural activations have been associated with conflict processing, it is unclear how specific any of these are to the type of stimulus conflict or the amount of response conflict. Here, we recorded electrical brain activity, while manipulating the type of stimulus conflict in the task (spatial [Flanker] versus semantic [Stroop]) and the amount of response conflict (two versus four response choices). Behaviorally, responses were slower to incongruent versus congruent stimuli across all task and response types, along with overall slowing for higher response-mapping complexity. The earliest incongruency-related neural effect was a short-duration frontally-distributed negativity at $\sim 200 \mathrm{~ms}$ that was only present in the Flanker spatial-conflict task. At longer latencies, the classic fronto-central incongruency-related negativity ' $\mathrm{N}_{\text {inc' }}$ ' was observed for all conditions, but was larger and $\sim 100$ ms longer in duration with more response options. Further, the onset of the motor-related lateralized readiness potential (LRP) was earlier for the two vs. four response sets, indicating that smaller response sets enabled faster motor-response preparation. The late positive complex (LPC) was present in all conditions except the two-response Stroop task, suggesting this late conflict-related activity is not specifically related to task type or response-mapping complexity. Importantly, across tasks and conditions, the LRP onset at or before the conflict-related $\mathrm{N}_{\mathrm{inc}}$, indicating that motor preparation is a rapid, automatic process that interacts with the conflict-detection processes after it has begun. Together, these data highlight how different conflict-related processes operate in parallel and depend on both the cognitive demands of the task and the number of response options.
\end{abstract}

(c) 2016 Elsevier Ltd. All rights reserved.

\section{Introduction}

A hallmark of cognitive control in humans is the ability to distinguish information that is relevant and important for behavior from information that is irrelevant or conflicting, and to respond accordingly. To do this successfully, the relevant stimulus must first be selected from multiple competing inputs, and then an appropriate response must be selected from an array of possibilities. Such selection processes have been studied using tasks such as the Stroop (Stroop 1935) and Flanker (Eriksen \& Eriksen, 1974)

\footnotetext{
* Corresponding author at: Department of Neurology, Leibniz Institute for Neurobiology, Otto-von-Guericke-University Magdeburg, Leipziger Strasse 4439120 Magdeburg, Germany.

E-mail address: donohue.sarah.e@gmail.com (S.E. Donohue).
}

that pit multiple stimulus inputs and/or output possibilities against each other. These conflict tasks can provide insight into the underlying neural mechanisms that occur from the stimulus-input to the response-output processes, and how such mechanisms can be modulated by different types and different levels of complexity of stimulus conflict and response competition.

Although both the Stroop and the Flanker tasks involve conflict, the types of conflict that are elicited by the respective stimuli in these tasks have some fundamental differences. In a typical Stroop task, a color word is written in a font color that either does or does not match the semantic meaning of the word (e.g., "Blue" written in blue ink versus "Blue" written in red ink), where the task is to identify the ink color while ignoring the irrelevant meaning of the word (see MacLeod, 1991 for review). Thus, the conflict occurs at the semantic level in this task, with the word meaning conflicting 
with the semantic representation of the ink color (e.g., Klein, 1964; La Heij, 1988). In contrast, conflict in a Flanker task occurs spatially instead of semantically. The stimuli in the Flanker task typically consist of a string of characters, the central one of which must be identified and the lateral ones ignored (Eriksen \& Eriksen, 1974). The lateral characters can match (i.e., be congruent with) or differ from (i.e., be incongruent with) the central character, thereby providing conflicting input from a nearby spatial location (Eriksen \& Schultz, 1979) that is not semantic in nature.

In addition to the competing stimulus input in the Stroop and Flanker tasks, conflict can be present at the level of the response. In the Stroop task, for example, a participant responding manually must make a button press corresponding to the correct ink color, where each button may represent a different response option (i.e., the name of a particular font color used in the task; e.g., Keele, 1972; Liotti, Woldorff, Perez, \& Mayberg, 2000). There are several different ways in which response conflict has been studied. For the purposes of the present study we will refer to the number of response options present as reflecting the amount or complexity of response-level conflict, under the view that if a correct response must be selected from more possibilities, then a higher level conflict would be expected to be present during response selection (La Heij \& van den Hof, 1995).

Regardless of the type of stimulus conflict and response conflict, the ultimate outcome of the presence of conflict is a decrement in behavioral performance, manifested as slower response times (RTs) and/or lower accuracy for incongruent compared to congruent trial types (Fan, Flombaum, McCandiss, Thomas, \& Posner, 2003; Kahneman \& Chajczyk, 1983; Zhang \& Kornblum, 1998). The competition of different stimulus and response representations (see Botvinick, Braver, Barch, Carter, \& Cohen, 2001; Cohen, Dunbar, \& McClelland, 1990; Zhang, Zhang, \& Kornblum, 1999 for modeling work on this topic) has been more recently studied with neural measures to investigate the underlying conflict-processing mechanisms in the brain (see Egner, 2007 and Larson, Clayson, \& Clawson, 2014 for reviews).

In EEG studies of conflict processing, where the precise timing of incongruency-processing effects can be identified, two main signatures of incongruency (incongruent vs. congruent trials) have typically been observed. The first signature is an early, frontalcentral, negative-going deflection, with incongruent trials eliciting more negative-polarity activity than congruent trials (e.g., West \& Alain, 1999; 2000). The second incongruency-related effect occurs later in time, appearing as a longer-latency posterior positivity complex (referred to here as the LPC; e.g., Liotti et al., 2000). Both of these components, and their putative roles in the Stroop and Flanker tasks, are discussed below.

Forms of the early negativity have been observed across a variety of conflict tasks (e.g., Appelbaum, Meyerhoff, \& Woldorff, 2009; Appelbaum, Smith, Boehler, Chen, \& Woldorff, 2011; Badzakova-Trajkov, Barnett, Waldie, \& Kirk, 2009; Bartholow et al., 2005; Beste, Saft, Andrich, Gold, \& Falkenstein, 2008; Coderre, Conklin, \& van Heuven, 2011; Killikelly \& Szúcs, 2013; Tillman \& Wiens, 2011; van Veen \& Carter, 2002a, 2002b). In some instances, this negativity has been termed the N450 in the Stroop task (e.g., West \& Alain, 2000), as it tends to peak at approximately $450 \mathrm{~ms}$ post-stimulus onset). In cases where the timing of this effect might vary, others have referred to this effect as the $N_{\text {inc }}$, standing for the negative-polarity incongruency wave without regard to a specific latency (e.g., Appelbaum et al., 2009; Appelbaum, Boehler, Davis, Won, \& Woldorff, 2014; Coderre et al., 2011). In the Flanker task, a negative-polarity component that is similar in distribution, often referred to as the N2, tends to occur slightly earlier in time (typically around 250-350 ms; Appelbaum et al., 2011; Bartholow et al., 2005; Danielmeier, Wessel, Steinhauser, \& Ullsperger, 2009; Frühholz, Godde, Finke, \& Herrmann, 2011; Tillman \& Wiens,
2011). Although sources of these conflict-related negativities have been linked to activity in the anterior cingulate cortex (ACC; Liotti et al., 2000; van Veen \& Carter, 2002b), it is not at all clear if the $\mathrm{N} 450$ and the N2 reflect different processes or are the same process occurring at slightly different time periods due to the nature of the task, or if they entail different subregions of the ACC or other brain areas and therefore potentially subserve fundamentally different mechanisms (Folstein \& Van Petten, 2008).

In considering the $\mathrm{N} 450 / \mathrm{N}_{\mathrm{inc}}$ and the $\mathrm{N} 2$, the question arises as to what the specific functional processes these electrophysiological components reflect. Although they are all observed in conflict tasks, and their frontocentral distributions are roughly similar, the timing of these effects does substantially differ in different circumstances. It is also entirely possible that spatial and semantic conflict might invoke different conflict detection and resolution processes, as the attentional allocation to resolve each of these types of conflict would presumably entail different suppression mechanisms for irrelevant information. As such, the cascade and timing of these effects could differ as a function of the type of conflict to be resolved.

Another possibility for the varying timing of the early conflictrelated negativity, is that instead of reflecting stimulus conflict and appearing as slightly different electrophysiological markers in the Stroop and Flanker tasks, these components may be sensitive to response-conflict differences between the two tasks. In EEG studies employing the Stroop task, the number of response options is typically greater than that in the Flanker task. Specifically, Stroop tasks used for EEG typically have had four response options (Appelbaum et al., 2014; Atkinson, Drysdale, \& Fulham, 2003; Badzakova-Trajkov et al., 2009; Coderre et al., 2011; Hanslmayr et al., 2008; Huster et al., 2009; Liotti et al., 2000; Markela-Lerenc et al., 2004; Silton et al., 2010; Tillman \& Wiens, 2011; West \& Alain, 1999; 2000 but see Caldas, Machado-Pinheiro, Souza, Motta-Ribeiro, \& David, 2012; Killikelly \& Szúcs, 2013), whereas EEG studies of the Flanker task have tended to only use two response options (Appelbaum et al., 2011; Bartholow et al., 2005; Beste et al., 2008; Brydges et al., 2012; Danielmeier et al., 2009; Freitas, Banai, \& Clark, 2009; Frühholz et al., 2011; Tillman \& Wiens, 2011; Wendt, Heldmann, Münte, \& Kluwe, 2007). Having a limited set of response-options, as in the Flanker task, could be the cause of an earlier onset of this conflict-related activity, which could explain the differential timing of the incongruency-related negativity that has observed in these two tasks. Relatedly, in a previous auditory version of the Stroop task in which there were only two response options, we observed that the early incongruency negativity effect also onset somewhat earlier, starting at around $200 \mathrm{~ms}$ (Donohue, Liotti, Perez, \& Woldorff, 2012). One potential reason for such an early onset might have been it being in the auditory domain, but another possibility is that only two response options were used in that study.

The longer-latency electrophysiological hallmark of conflict processing is a late posteriorly-distributed positive wave, termed the late positive complex, or LPC (also sometimes called the "conflict slow potential" or SP), which is greater for incongruent compared to congruent trials. This activation is typically fairly long in duration, onsetting at approximately $500 \mathrm{~ms}$ and lasting up until 900-1000 ms post-stimulus-onset (e.g., Appelbaum et al., 2009; Coderre et al., 2011). It has been postulated that this component, which tends to be left-sided, may reflect some sort of semantic interpretation (c.f., Liotti et al., 2000), or that it may reflect the up-regulation of attention in its role in conflict adaption, with the RT behavioral effect and the incongruency-related neural effect on the LPC both being stronger on an incongruent trial that was preceded by a congruent versus an incongruent trial (Donohue et al., 2012; Larson, Kaufman, \& Perlstein, 2009). This component may also be task-specific, as it is has mainly been observed 
(or at least reported) in EEG studies of the Stroop task (Appelbaum et al., 2009; Coderre et al., 2011; Hanslmayr et al., 2008; Huster et al., 2009; Liotti et al., 2000; Markela-Lerenc et al., 2004; West \& Alain, 1999; 2000), with only one study of the Flanker task reporting a small and rather brief version of such a component (Appelbaum et al., 2011).

An additional ERP marker that is quite useful when considering various types of conflict processing is the lateralized-readiness potential (LRP; Coles, 1989; Gratton et al., 1988). This component is not related to incongruency processing per se, but rather reflects the timing of motor-response preparation (see Leuthold, Sommer, \& Ulrich, 2004, for review). The LRP is obtained by taking the trials for which a right-hand response was made versus trials for which a response with the left hand was made, and comparing their respective activity over lateral central sites, with the source of this difference likely arising from motoric regions such as the supplementary motor area (SMA; Praamstra, Stegeman, Horstink, \& Cools, 1996). In studies of conflict processing, the LRP has been used to determine the differences in the onset and time course of response preparation, to examine these differences as a function of congruency or age or other factors (e.g., Ridderinkoff \& van der Molen, 1995; Lansbergen \& Kenemans, 2008). Ridderinkoff and van der Molen (1995) observed the LRP onset later for incongruent trials as compared to congruent or neutral trials in a Flanker task, confirming that interference can manifest in slowed responsepreparation initiation.

Although the role of the LRP in motor-response preparation has been well characterized, the precise functional meanings of the conflict-associated neural activations and their relationships to motor-response preparation are still not clear. We therefore implemented a fully-crossed within-subject design with Stroop and Flanker tasks, each with two or four response options. We examined the onsets and time courses of key ERP components elicited by these tasks using permutation statistics: the conflictrelated $\mathrm{N} 2 / \mathrm{N}_{\text {inc }}$ and LPC, as well as the response-related LRP. If any of these ERP components are sensitive to the type of stimulus conflict, then we would expect to see modulations of the onset, duration, and/or magnitude as a function of task. In addition, to the extent that these components are sensitive to response conflict, they should be modulated by the number of response choices present, independent of the task that was implemented.

Based on previous findings, several predictions of outcomes from this design can be made. First, as the N2 effect has principally been observed in the Flanker task, we expect that this earliest conflictrelated activity will be present only in this task. If this were the case, it would suggest the importance of this component in spatial conflict detection and/or resolution, and, if it is not modulated by response number, that it is not related to this form of response conflict. Second, if the $\mathrm{N}_{\text {inc }}$ is related to response conflict, then it should have a longer duration, regardless of task, in the four-response-choice conditions compared to the two-response-choice conditions. Third, if the LPC is related to the resolution of conflict and/or preparation for the upcoming trial, then we would expect to see the strongest presence of this component for tasks that appeared to be more difficult behaviorally. Finally, the LRP index of motor preparation should onset later or perhaps last longer when there are more response options from which to select.

\section{Methods}

\subsection{Participants}

Data from 32 healthy individuals are included in this study (18 male, mean age $=23.3+/-4.4$ years, 2 left-handed). Data from nine additional participants were excluded due to excessive blinking or eye movements in one or more of the tasks. All of the included individuals had normal or corrected-to-normal visual acuity, and none were colorblind. All participants gave written informed consent and were compensated for their time at a rate of $\$ 15 /$ hour. The participants were members of either the Duke University community or the surrounding local community (i.e., Durham, NC), and they were recruited through an online participation website maintained by the Center for Cognitive Neuroscience at Duke University. The procedures used in this study were approved by the Institutional Review Board of the Duke University Health System.

\subsection{General task structure}

Each participant completed two tasks (the Stroop task and the Flanker task), each with two different response sets (two response choices or four response choices), in different blocks over the course of the experiment. The order of the blocks (and thus the tasks and response configurations) was randomized and counterbalanced across participants. Importantly, the order of the tasks was implemented such that participants would never switch back and forth between the Stroop and Flanker tasks, and the task conditions were blocked such that a participant would not switch back and forth between the two and four response mapping conditions within a task. This was done to prevent general confusion concerning the tasks, in order to have the conflict processes we were examining be due to the specific task/response options and not the result of constant task-switching or task-switching confusion. An example of the task order could be: Flanker fourresponse choice, Flanker two-response choice, Stroop two-response choice, Stroop four-response choice. Another example is shown in part $\mathrm{C}$ of Fig. 1.

All participants performed a practice block of trials each time the task or response configurations was switched. Performance during the practice block (and during the experiment) was monitored online through a behavioral analysis script, which was running in parallel to the experiment. If participants did not feel comfortable with the response configuration, or if the behavioral performance indicated poor accuracy, practice blocks were repeated until the participants could easily implement the response configurations.

\subsection{Stimuli}

\subsubsection{Stroop task}

The Stroop stimuli consisted of colored rectangles that subtended 5 by 16 degrees of visual angle (see Appelbaum et al. 2009; 2012; 2014; for previous studies with similar stimulus configurations), presented 3.75 degrees below fixation (see Fig. 1). Each colored rectangle contained a color word written in white ink. The stimuli could be congruent (50\% of trials), where the physical color of the rectangle and the semantic meaning of the word matched (e.g., the word "RED" written on a red rectangle) or they could be incongruent where the rectangle color and word did not match (e.g., the word "BLUE" written on a red rectangle). The words and physical colors were red, blue, green, yellow, purple, pink, orange, and brown. The stimulus structure used in this task, therefore, differed somewhat from those often used in most Stroop tasks (e.g., Liotti et al., 2000), in which the word is written in the font color that either matched or did not match its semantic meaning. We chose to use the bar/word stimuli here, in order to be able to compare our ERP activation patterns with that which we had previously observed in a version of the Stroop task where we had used such a stimulus structure in order to give us the ability to vary the relative 
A.

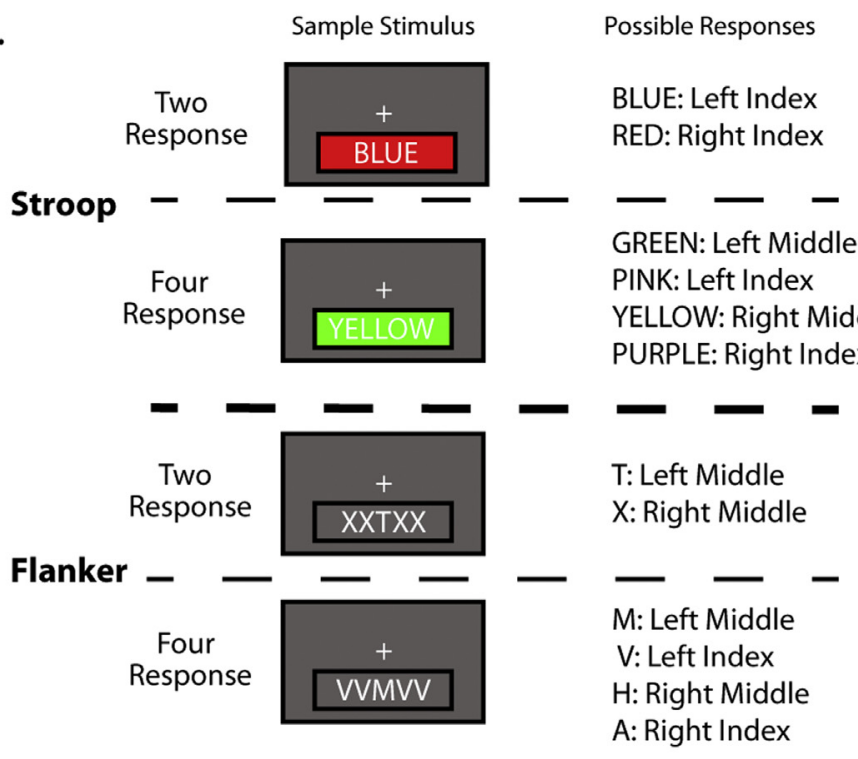

B.

Sample

Trial Sequence (Stroop
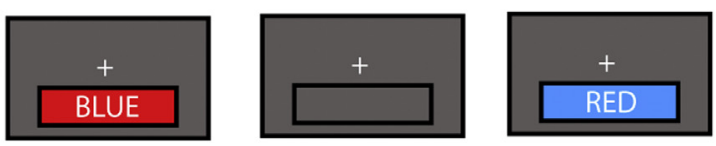

Trial)

$1000 \mathrm{~ms}$

300-700 ms

$1000 \mathrm{~ms}$

c.

Example Experimental Session

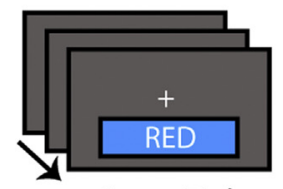

Stroop Task

Two Response

Choice Block

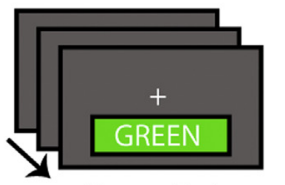

Stroop Task

Four Response

Choice Block

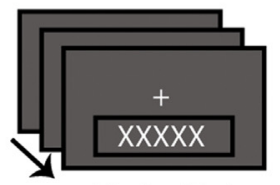

Flanker Task

Two Response

Choice Block

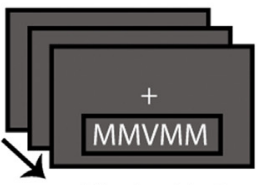

Flanker Task

Four Response

Choice Block

Time

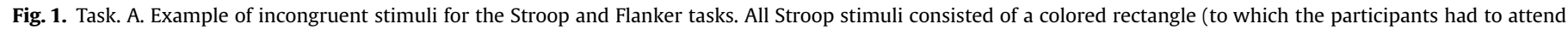

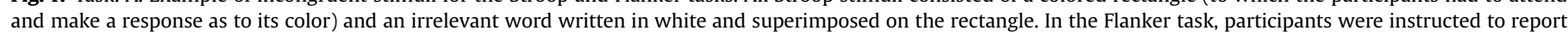

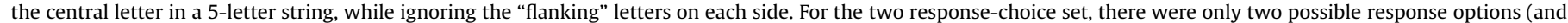

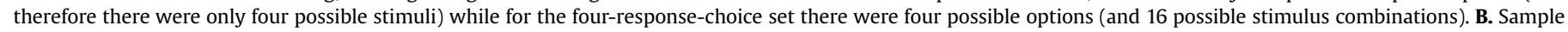

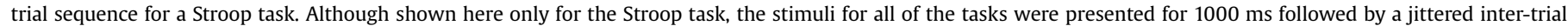

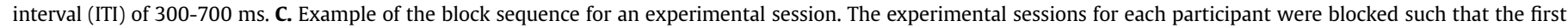

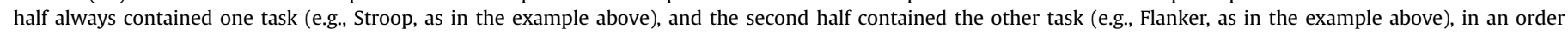

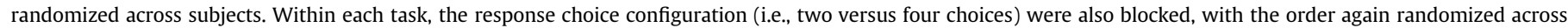
subjects). Each block (e.g., Stroop Task Two Response Choice Block) consisted of four runs of trials, with short breaks between each run.

temporal onsets of the color/word information (Appelbaum et al., 2009; 2012; 2014). This previous work had confirmed that such Stroop stimuli do elicit robust incongruency effects, both behaviorally and neurally, in line with that which has been observed with the more traditional Stroop stimuli (Liotti et al., 2000).

All stimuli were rotated across participants such that they appeared with equal frequency across conditions and participants, and each participant was randomly assigned a set of six color stimuli (four stimuli for the four-response-choice set, two stimuli for the two-choice-response set). For a given participant, the stimuli used in the blocks with a two-response-choice set were never the same as those used in the blocks with the four-responsechoice set.

\subsubsection{Flanker Task}

The Flanker stimuli were similar to those used by Appelbaum et al., 2011, and consisted of a row of five letters with the central letter being the target letter. The Flanker stimuli were presented inside the same visual area as the Stroop stimuli and therefore subtended 5 by 16 degrees (see Fig. 1). Half of the trials were congruent (where the central letter matched the lateral flanking letters "XXXXX") and half were incongruent (where the central letter did not match the flanking letters "XXMXX"). The letters used across all participants were X, I, T, A, V, H, M, and Y. As with the Stroop task, the stimuli used in the blocks with a two-response-choice set were never the same as those used in the blocks with a four-response-choice set for a given participant. All stimuli were rotated across participants such that they appeared with equal frequency across conditions and participants, and each 
participant was randomly assigned a set of six stimuli (four for the four-response-choice set and two for the two-response-choice set).

\subsection{Procedure.}

\subsubsection{Stroop task}

In both the two-response-choice set and four-response-choice set, participants were asked to identify the physical color of the rectangle while ignoring the written word. Each trial consisted of the colored rectangle and word appearing simultaneously on the screen and remaining there for $1000 \mathrm{~ms}$. The inter-trial-interval was jittered from 300 to 700 ms. Each run consisted of 96 trials of Stroop stimuli, such that there were 192 congruent and 192 incongruent trials randomly presented over the course of the four runs for the two-response-choice set blocks and over the course of the four runs for the four-response-choice set blocks.

\subsubsection{Flanker task}

In both the two-response-choice set and four-response-choice set configurations, participants were asked to identify the middle letter of a 5-letter string while ignoring the four surrounding letters. The trial structure, counterbalancing, and number of trials for the Flanker task were identical to the Stroop task, described above.

\subsubsection{Response mapping}

In order to ensure that participants were not systematically biased in the two-response-choice set, due to using more or less dominant fingers, the following cross-subject response-mapping procedure was implemented for the two-responses tasks. One quarter of the participants responded with their index fingers of their left and right hands for the Stroop task and their middle fingers for the Flanker task. Another quarter of participants were given the opposite response configuration, responding with their middle fingers of their left and right hands for the Stroop task and their index fingers for the Flanker task. For the last two quarters of participants, the finger-dominance was counterbalanced within task. Specifically, the third quarter of participants responded to the first two blocks with their index fingers and to the second two blocks with their middle fingers for the Stroop task (with the opposite mapping order for the Flanker task). The final quarter of participants responded to the first two blocks using their middle fingers and to the second two blocks using their index fingers for the Stroop task (with the opposite mapping order for the Flanker task). Reaction times and accuracy did not differ based on the response finger used in the two-response choice conditions, and response finger did not interact with any other experimental factor. Accordingly, data were collapsed across this factor for the results reported here. Of note, such a response-counterbalancing was not implemented in the four-response choice tasks, as having four response options inherently forced participants to use both the index and middle fingers of their left and right hands. All responses were made using a game controller, for which the buttons used were located on the back of the controller.

\subsection{Behavioral analysis}

Trials were excluded from behavioral analysis if a response was not produced between 200 and 1200 ms after the stimulus onset (1.2\% of total trials), or if there was an EEG artifact during that epoch ( $15.1 \%$ of remaining trials). This left an average of $84 \%$ of trials in the analysis, or an average of 161 trials per participant for each condition for each task. All results were considered significant at alpha levels below 0.05 , unless otherwise specified.

\subsection{EEG data collection and analysis}

\subsubsection{Data acquisition}

EEG data were collected with a 64-channel custom-designed cap (Electrocap International Inc., Eaton, OH, USA) using a Neuroscan system (Neuroscan/Compumedics, Inc., Charlotte, NC, USA). The data were referenced to the right mastoid during recording, and then re-referenced offline to the algebraic average of the left and right mastoids. All impedances were maintained below $5 \mathrm{kOhms}$, with the exception of the ground electrode (located within the cap) and the left and right mastoids, which were maintained below $2 \mathrm{kOhms}$. Data were digitized at a rate of $500 \mathrm{~Hz}$ per channel, with a gain of 10,000 , and were filtered online with a bandpass from 0.01 to $100 \mathrm{~Hz}$.

\subsubsection{ERP analyses}

The data were analyzed offline using EEGLAB (Delorme \& Makeig, 2004) and ERPlab (Lopez-Calderon \& Luck, 2014). Each epoch was obtained from $500 \mathrm{~ms}$ prior to $1400 \mathrm{~ms}$ after the event of interest (i.e., the onset of the Stroop or Flanker stimuli), and only trials which contained a correct response occurring within 200$1200 \mathrm{~ms}$ post-stimulus onset were retained for further processing. Trials containing excess physiological noise (e.g., eye blinks, muscle tension, eye movements, etc.) were excluded from the EEG analysis. Specifically, after the data had been epoched, the data were run through an algorithm that implemented a peak-to-peak threshold artifact detection method (in $20 \mathrm{~ms}$ steps) for each subject, using -250 to $1100 \mathrm{~ms}$ as the time period over which artifacts should be eliminated. The data were then plotted and visually inspected to determine if the thresholds were appropriate (i.e., were picking up artifacts effectively), and if they were not, the thresholds and window width/steps were then modified and the artifact-marking routine was rerun until an effective threshold had been reached for each channel to get rid of trials containing artifacts. These adjustments were performed in a manner that was blind to which epoch belonged to which condition. The final threshold values ranged from 48 to $215 \mathrm{uV}$, with a mean percentage of $15.5 \%$ trials being rejected. The rejection rates did not differ across the Stroop and Flanker tasks (Stroop $=15.1 \%$, Flanker $=15.9 \% ; t(31)=0.42, p=.67$ ). Additionally a routine was run to determine if any channels flatlined during the experiment, and such channels were subsequently interpolated by the average of the neighboring channels if this were the case. The trials which remained after artifact rejection were then averaged and then filtered using an IIR Butterworth low-pass filter with $30 \mathrm{~Hz}$ as the half-amplitude point. For both plotting and statistical analyses, the ERP averages were baseline corrected from -200 to 0 .

As has been previously observed in conflict-related tasks, two main conflict-related processing components of interest emerged (see Appelbaum et al., 2014; Liotti et al., 2000). The first component was the intermediate-latency, centrally-distributed, incongruency-related negativity, the " $\mathrm{N}_{\text {inc }}$ ", peaking between 300 and $500 \mathrm{~ms}$, and the second component was the longer-latency, posteriorally-distributed late positive complex, the "LPC." For each of these components, the data were collapsed across the two response conditions (i.e., the two and four response-choice conditions) for each task to obtain an ROI for the $\mathrm{N}_{\text {inc }}$ and for the LPC (see Supplementary Figure 1). For both tasks, the topographic maximum of the $\mathrm{N}_{\text {inc }}$ was centered around channels $\mathrm{FCz} / \mathrm{Cz}$ and therefore an ROI of these 2 channels and the 2 surrounding lateral channels $\mathrm{C} 1 \mathrm{a} / \mathrm{C} 2 \mathrm{a}$ was generated for analyses. The maximum of the LPC across all conditions was centered around channels $\mathrm{POz} /$ $\mathrm{Pz}$, and therefore an ROI was generated from these sites and the 2 surrounding lateral channels, $\mathrm{PO} 1 / \mathrm{PO} 2$. In addition to the $\mathrm{N}_{\text {inc }}$ and the LPC, an earlier negative-polarity incongruency-related effect was observed over frontal electrode sites, which was 
statistically tested using in an ROI centered around Fz (see Supplementary Figure 1).

The lateralized readiness potential (LRP), a signature of motorresponse preparation over the motor cortices, was obtained for all conditions and subjects. This component was computed by taking the difference between the event-related responses at sites contralateral versus ipsilateral to the hand used to respond on a given trial. Specifically, the LRP was extracted at sites $\mathrm{C} 4 / \mathrm{C} 4 \mathrm{a} / \mathrm{C} 2 \mathrm{a}$ and $\mathrm{C} 3 / \mathrm{C} 3 \mathrm{a} / \mathrm{C} 1 \mathrm{a}$ by taking the ERP activity from the sites that were ipsilateral to a motor response and subtracting it from the ERP activity from the corresponding sites that were contralateral to a response. This subtraction was done separately for trials in which a response was made with the left hand and for those trials in which a response was made with the right hand. Once the contralateralminus-ipsilateral values had been obtained for the left-hand responses and for right-hand responses, the data were averaged together to obtain contralateral-minus-ipsilateral activity levels collapsed across the two hands. Of note, the LRP was time-locked to the stimulus onset such that its onset latency could be appropriately contrasted with that of the other components of interest.

\subsubsection{Statistical analyses of ERPS}

For all of experimental contrasts, ERP significance was assessed using permutation statistics to determine the onset and duration of each effect. Although this analysis does not always capture the effects in the way that an ANOVA might, given the temporal overlap of some of these activations, as well as their temporal variations as a function of the different conditions, the permutation tests were less biased than a moving-window ANOVA might have been. In these permutation tests, the congruent and incongruent data labels for a specific condition (e.g., Stroop two-response choice congruent vs. Strooptwo-response choice incongruent) were randomized and permuted 10,000 times, and the t-statistic was obtained for each of these permutations. This created a bootstrap distribution for each time point. The t-value obtained from the real data from the congruent and incongruent trial types was then compared with the t-values of the data from this distribution, and was considered significant if it fell within the top $2.5 \%$ or bottom $2.5 \%$ of the distribution on a sample-by-sample basis (Appelbaum, Wade, Vildavski, Pettet, \& Norcia, 2006; Groppe, Urbach \& Kutas, 2011; Nichols \& Holmes,
2002). To minimize the contribution of short spurious intervals that reached statistical significance, effects were only considered real and reported if they lasted a minimum of $10 \mathrm{~ms}$ (i.e., at least 5 sample points in a row; e.g., Schoenfeld et al., 2003).

The effects were tested over relatively broad time periods, in order to capture the onset and duration. Specifically, the early effect tested at the ROI around $\mathrm{Fz}$ was examined from 125 to $225 \mathrm{~ms}$, the $\mathrm{N}_{\text {inc }}$ effect was examined from 225 to $675 \mathrm{~ms}$, and the LPC was examined from 400 to $1000 \mathrm{~ms}$. For the LRP, permutation tests were performed from 100 to $700 \mathrm{~ms}$ post-stimulus. Of note, $700 \mathrm{~ms}$ is longer than the mean response time for any of the conditions. Although the LRP did appear to last longer than this time period (likely due to the variability both within and between participants in responding), we did not test it for significance beyond this point, as we were mainly interested in the onset of this component.

\section{Results}

\subsection{Behavioral data}

Participants were highly accurate in their performance across all tasks (see Fig. 2A). The error rates for each subject and trial type were submitted to a three-factor $(2 \times 2 \times 2)$ repeated-measures ANOVA, with the following factors: 'task' (Stroop vs. Flanker) by 'response set' (four choices vs. two choices) by 'congruency' (incongruent vs. congruent). All the main effects in these accuracy analyses were significant, with fewer errors on the Stroop than Flanker task (Stroop $\boldsymbol{M}=\mathbf{4 . 0 \%}, S D=2.2 \%$, Flanker $\boldsymbol{M}=\mathbf{5 . 8 \%}$, $\left.S D=4.1 \% ; F(1,31)=10.15, p=0.003, n_{\mathrm{p}}{ }^{2}=0.25\right)$, fewer errors on the two than on the four-response-choice set conditions (two-response: $\boldsymbol{M}=\mathbf{3 . 0 \%}, S D=2.7 \%$, four-response: $\boldsymbol{M}=6.7 \%, S D=4.0 \% ; F$ $\left.(1,31)=34.61, p<0.001, \eta_{p}^{2}=0.53\right)$, and fewer errors on the congruent than the incongruent trial types (congruent $\boldsymbol{M}=\mathbf{3 . 8 \%}$, $S D=2.3 \%$, incongruent $\boldsymbol{M}=\mathbf{6 . 0 \%}, \quad S D=3.7 \% ; \quad F(1,31)=31.73$, $\left.p<0.001, \eta_{\mathrm{p}}^{2}=0.51\right)$. Of note, direct post-hoc comparisons between the error rates for incongruent and congruent conditions for each task (i.e., two-response-choice Stroop, four-responsechoice Stroop, two-response-choice Flanker, four-response-choice Flanker) were all significant (all p's $<0.05$; see Supplementary
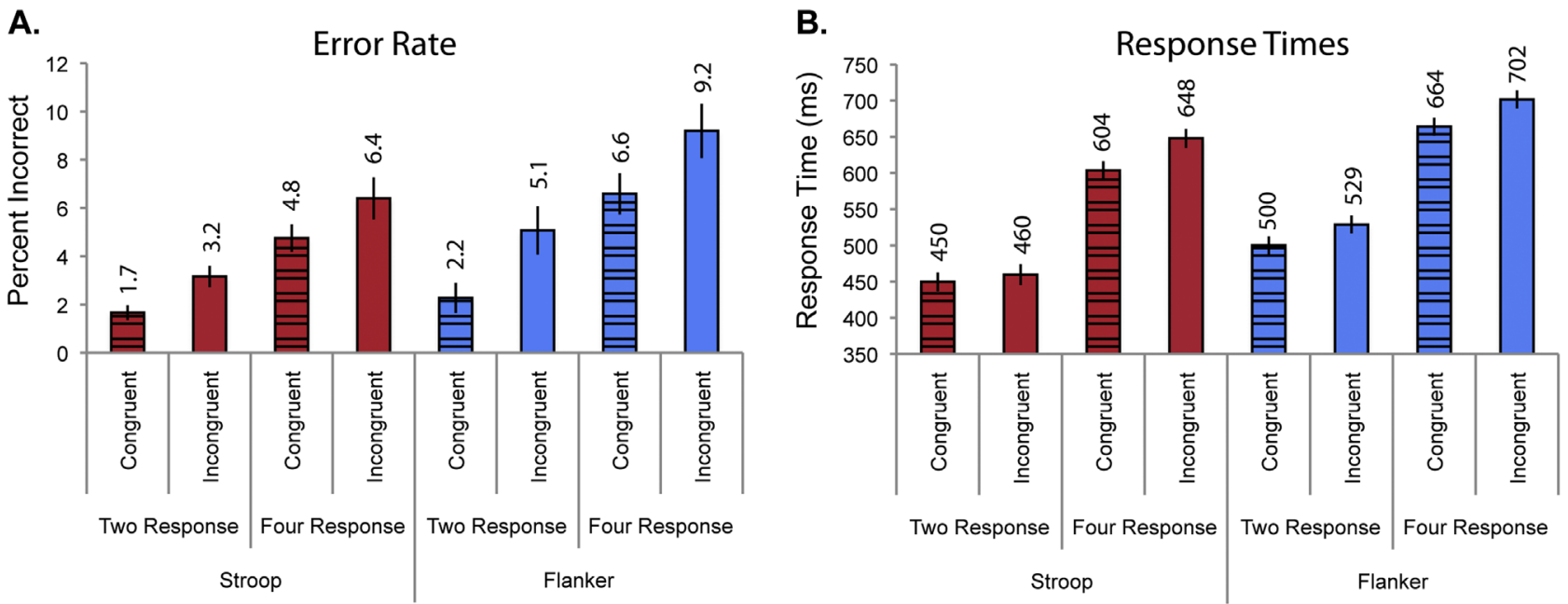

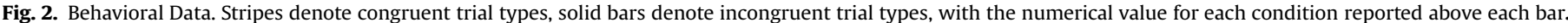

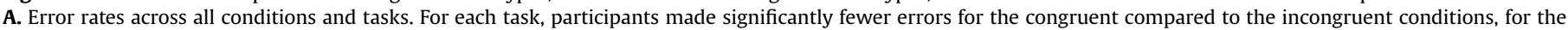

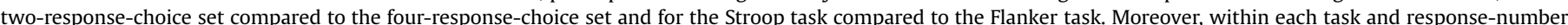

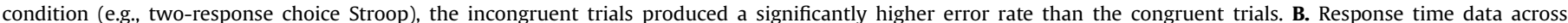

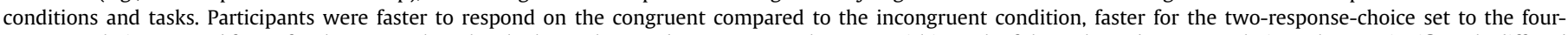

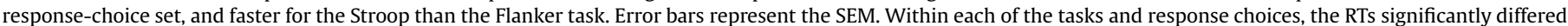
between congruent and incongruent trial types, with slower RTs to incongruent in every case. 
Table 1 for values). From the main ANOVA, there was a marginally significant interaction between task and congruency $(F(1,31)=$ $4.00, p=0.054, \eta_{\mathrm{p}}^{2}=0.11$ ), due to the Stroop task having somewhat smaller effects of congruency on error rates (e.g., less of a difference for incongruent vs. congruent) than did the Flanker task. No other significant interactions between any of these factors on accuracy were observed.

The mean response times (RTs) (see Fig. 2B) for each participant were submitted to $2 \times 2 \times 2$ repeated-measures ANOVA with the same factors as for the accuracy data. All main effects were significant in modulating the RT data, with faster RTs for the Stroop than the Flanker task (Stroop $\boldsymbol{M}=\mathbf{5 4 0} \mathbf{~ m s}, S D=71 \mathrm{~ms}$, Flanker $\boldsymbol{M}=\mathbf{5 9 9} \mathbf{~ m s}, S D=63 \mathrm{~ms} ; F(1,31)=39.23, p<0.001, \eta_{\mathrm{p}}{ }^{2}=$ 0.56 ), faster RTs for the two-response-choice set than the fourresponse-choice set (two-response $\boldsymbol{M}=\mathbf{4 8 5} \mathbf{~ m s}, S D=67 \mathrm{~ms}$, fourresponse $\boldsymbol{M}=\mathbf{6 5 4} \mathrm{ms}, S D=63 \mathrm{~ms} ; F(1,31)=564.88, p<0.001$, $\eta_{\mathrm{p}}{ }^{2}=0.95$ ), and faster RTs for the congruent trials than the incongruent trials (congruent $\boldsymbol{M}=\mathbf{5 5 4} \mathbf{~ m s}, S D=62 \mathrm{~ms}$; incongruent $\left.\boldsymbol{M}=\mathbf{5 8 4} \mathbf{~ m s}, S D=61 \mathrm{~ms} ; F(1,31)=185.15, p<0.001, \eta_{\mathrm{p}}{ }^{2}=0.86\right)$. Further, there was a significant interaction between response set and congruency (greater incongruency effects for four vs. tworesponse-choice: $\left.F(1,31)=37.70, p<0.001, \eta_{p}{ }^{2}=0.55\right)$ and a significant three-way interaction between task, response choice, and congruency (due to a greater incongruency effect in the four-response-choice compared to the two-response choice for the Stroop task as compared to the Flanker task: $F(1,31)=19.34, p<0.001$, $\eta_{\mathrm{p}}{ }^{2}=0.38$ ). Importantly, across all tasks and conditions, the incongruent trials were always significantly slower than the congruent trials at the Bonferroni-adjusted alpha level of 0.0125 (all $t$ 's $>3.63$ and $p$ 's $<0.002$; see Supplementary Table 1 for values).

\subsection{EEG data}

Visual inspection of the data revealed several different incongruency-related effects. For each of these effects, ROIs were created and permutation tests were run to determine the onsets and durations across the different tasks and conditions (see Methods section 2.6.3 for details). The earliest-latency incongruency effect was a frontal-central negativity at around $200 \mathrm{~ms}$ in the Flanker task. The second effect was a later (intermediate latency) and slightly more posterior negative-polarity wave, occurring at around $300 \mathrm{~ms}$ (here referred to as the $\mathrm{N}_{\text {inc }}$ ). The third incongruency related effect was a posterior parietal positivity (the LPC), occurring at around $600 \mathrm{~ms}$. Finally, the motor-preparation-related LRP was examined as a function of task and response-choice set.

\subsubsection{Early incongruency effect}

The earliest incongruency-related effect was significantly present only in the Flanker task. This effect was a brief negative deflection (incongruent more negative than congruent) in the prefrontal channels, onsetting just prior to $200 \mathrm{~ms}$ post-stimulus (Fig. 3). This early frontal negativity appeared to have a longer duration in the two-response-choice set than the four (see Table 1.); however, a comparison of the incongruent minus

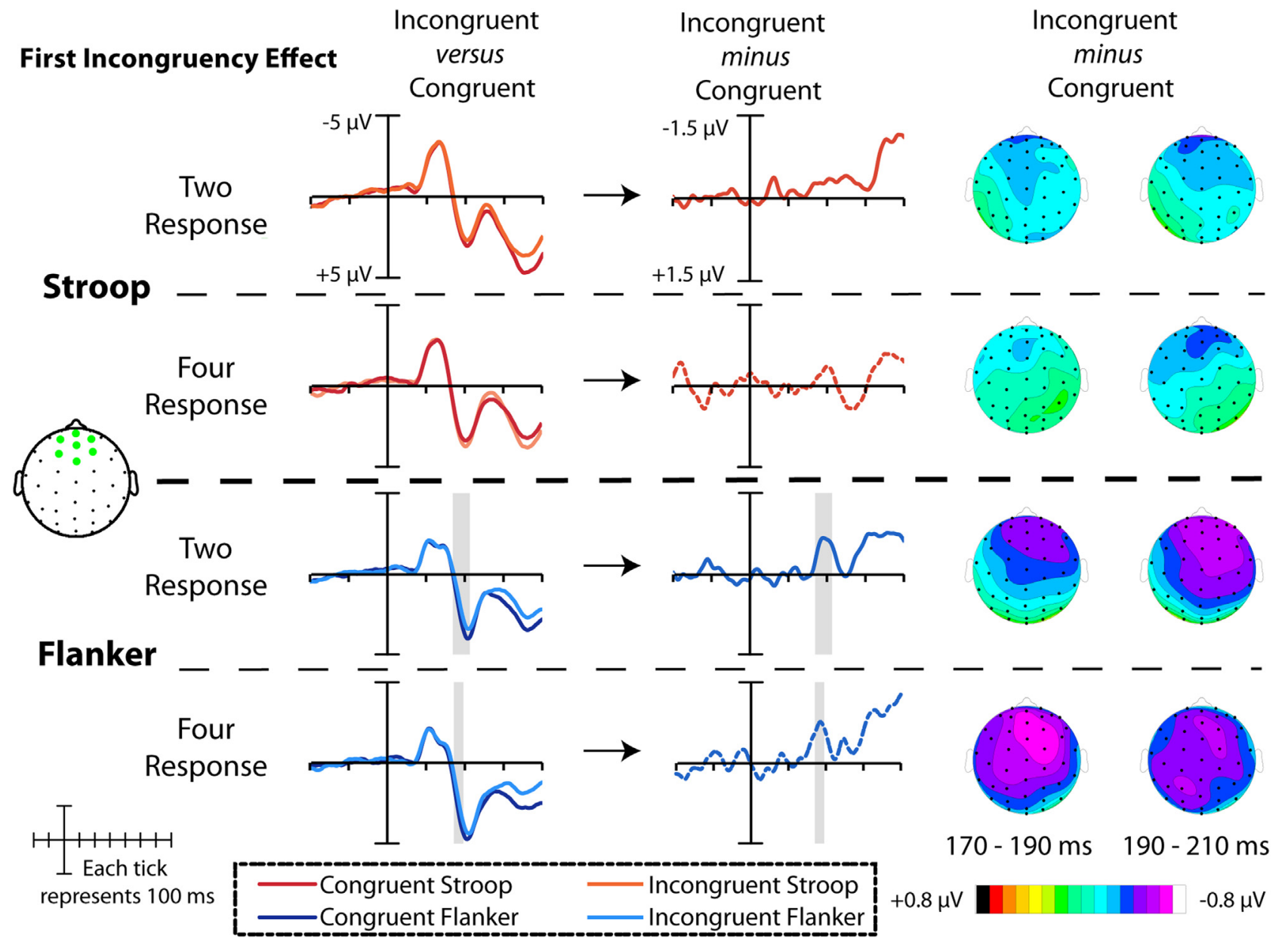

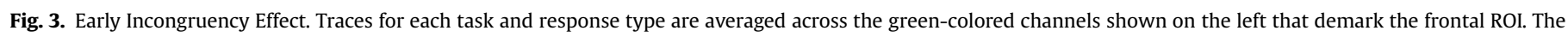

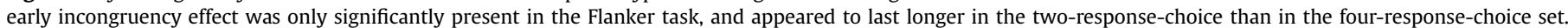
Periods of significant differences between incongruent and congruent trial types as determined by permutation tests are highlighted in grey. 
Table 1

Significant time periods for the first incongruency effect. The onset, offset, and duration are listed for each of the tasks and response configurations for the early incongruency effect in the frontal ROI shown in Fig. 3. Of note, there were no significant time periods of activation for the Stroop task in this ROI (n.s. =not significant).

\begin{tabular}{ccccc}
\hline Task & Response Set & Onset & Offset & Duration \\
\hline Stroop & Two & n.s. & n.s. & n.s. \\
Stroop & Four & n.s. & n.s. & n.s. \\
Flanker & Two & 173 & 211 & 38 \\
Flanker & Four & 177 & 195 & 18 \\
\hline
\end{tabular}

congruent difference waves for the two-response-choice vs. fourresponse-choice Flanker did not reveal any significant differences between the two conditions.

\subsubsection{Intermediate-latency incongruency effect $\left(N_{\text {inc }}\right)$}

The second incongruency-related effect was a longer-lasting frontal-central negativity, the $N_{i n c}$, that was present across all tasks and response configurations. Fig. 4 depicts the traces and difference waves for this effect, and the onsets, offsets, and durations are shown in Table 2 .

This intermediate-latency incongruency effect onset slightly earlier for the Flanker than the Stroop task, and was statistically significant for approximately $100 \mathrm{~ms}$ longer in the four compared to two response-choice configurations. To confirm the difference in onsets across tasks, we collapsed the incongruent minus congruent difference waves across response-choice, and then submitted the results to permutation tests for the Stroop task vs. Flanker. This revealed a significant difference between the $\mathrm{N}_{\text {inc }}$ of
Table 2

Latency ranges with significant permutation differences between congruent and incongruent conditions for the $\mathrm{N}_{\text {inc }}$ contrast. The onset, offset, and duration are listed for each of the tasks and response configurations for the frontocentral ROI.

\begin{tabular}{ccccc}
\hline Task & Response Set & Onset & Offset & Duration \\
\hline Stroop & Two & 325 & 535 & 210 \\
Stroop & Four & 323 & 621 & 298 \\
Flanker & Two & 287 & 385 & 98 \\
Flanker & Four & 303 & 479 & 176 \\
\hline
\end{tabular}

the two tasks from 289-327 ms, suggesting that the onset of the $\mathrm{N}_{\text {inc }}$ in the Flanker task was indeed earlier than that of the Stroop. Moreover, the $\mathrm{N}_{\text {inc }}$ for the Stroop task had a longer duration in than it did in the Flanker task, with permutation tests showing these waves differed from each other between 445-625 ms. To determine if the four-response choice configuration was significantly longer than the two-response choice configuration, we ran specific permutation tests on the incongruent minus congruent difference waves on the two-response-choice vs. the fourresponse-choice sets for each task respectively. For the Stroop task, the difference lasted only $12 \mathrm{~ms}$ (from 548-560); however, in the Flanker task the two and four response choice configurations differed significantly for $112 \mathrm{~ms}$ (from 408-520).

Additional analyses examined the relationship between the neural incongruency effects and behavior. These showed that in the four-response choice condition of the Stroop task, there was a significant correlation between the $\mathrm{N}_{\text {inc }}$ (as a difference wave) and incongruent minus congruent RT differences across participants $(r=-0.45, p=0.01)$, where participants with the largest

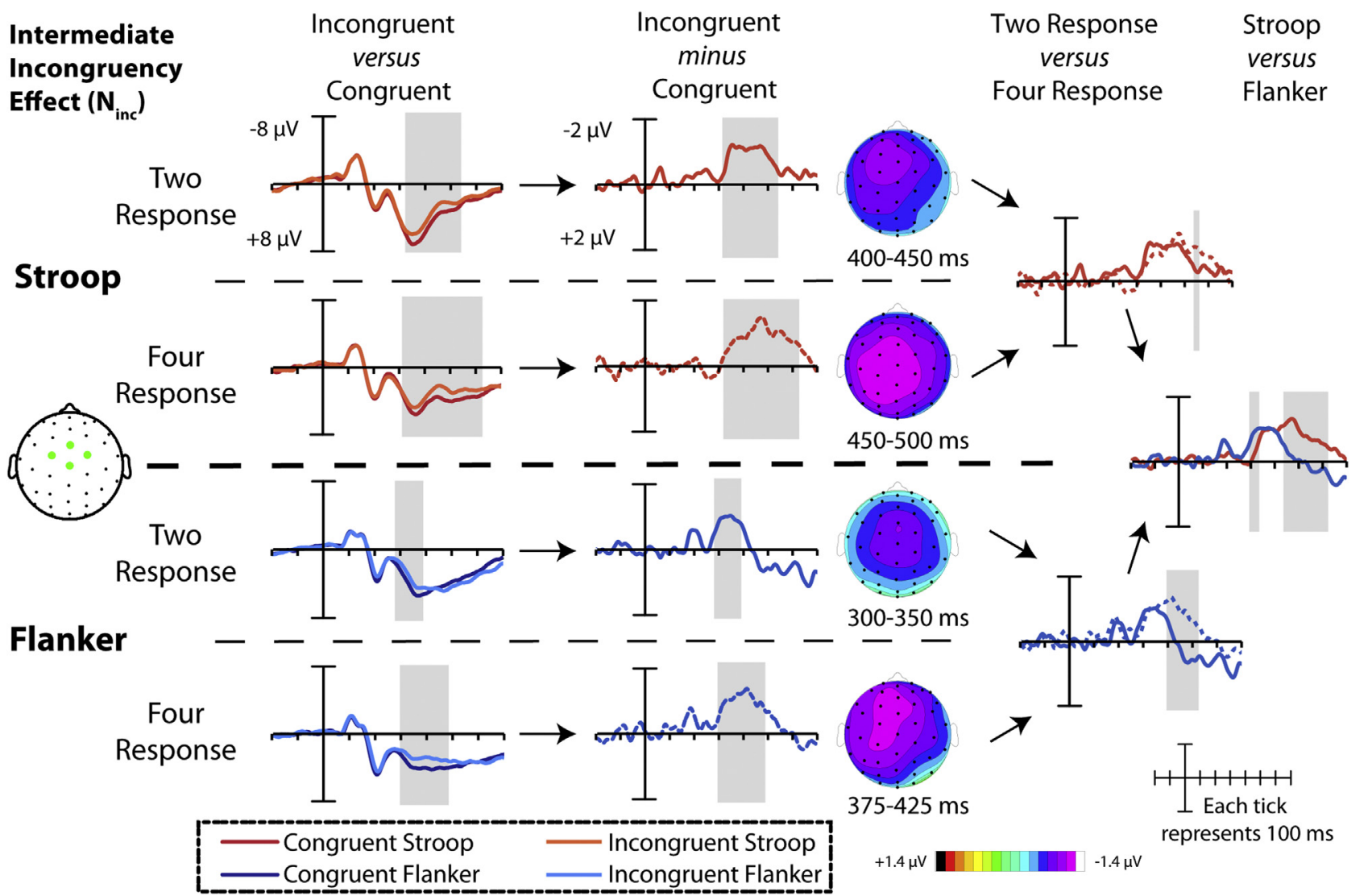

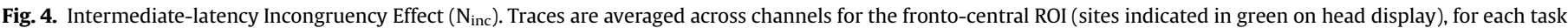

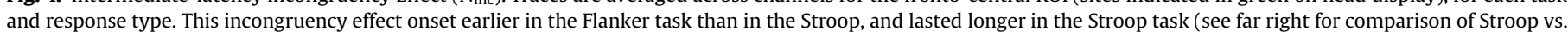

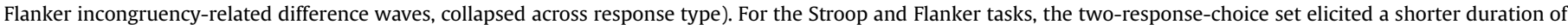
this frontal-central incongruency negativity, as compared to the four-response-choice set. Periods of significant differences are highlighted in grey. 
Table 3

Latency ranges with significant permutation differences between congruent and incongruent conditions for the LPC contrast. The onset, offset, and duration are listed for each of the tasks and response configurations for the parietal ROI (shown in Fig. 5).

\begin{tabular}{ccccc}
\hline Task & Response Configuration & Onset & Offset & Duration \\
\hline Stroop & Two & 778 & 814 & 36 \\
& & 868 & 920 & 52 \\
Stroop & Four & 988 & 1000 & 12 \\
& & 630 & 960 & 330 \\
Flanker & Two & 986 & 1000 & 14 \\
Flanker & Four & 460 & 722 & 262 \\
& & 566 & 592 & 26 \\
& & 614 & 770 & 156 \\
& & 784 & 900 & 116 \\
& & 990 & 1000 & 10
\end{tabular}

incongruency RT effect also having the largest $\mathrm{N}_{\text {inc }}$ amplitude effect. None of the other conditions showed significant correlations between ERP amplitudes and behavioral performance.

\subsubsection{Late positive complex ( $L P C$ ) incongruency effect}

The incongruency effect on the LPC (where incongruent trial types were more positive than congruent) varied across tasks and response options. This effect was present in the Stroop and Flanker tasks in which there were four response options, as well as for a slightly shorter total duration in the Flanker task with two response options. However, it was present for only a few brief periods in the two-response Stroop task. Of note, this late-positivity was not entirely stable in terms of significance, with brief periods of non-significance in both the Stroop and Flanker tasks. Table 3 shows the time windows for which this effect was significant, and Fig. 5 depicts the traces and topographic distributions across tasks and response type.

\subsubsection{LRP analysis}

For the two-response choice Stroop task, the onset of the motor-preparation-related LRP occurred at $172 \mathrm{~ms}$, whereas for the four-response choice Stroop task it began at $222 \mathrm{~ms}$ (see Fig. 6). The same pattern was observed in the Flanker task, where the two-response choice LRP onset prior to the four-response-choice ( $230 \mathrm{~ms}$ vs. $286 \mathrm{~ms}$; however both of these LRPs had brief periods of earlier statistical significance prior to the onset of the main effect (170-186 ms for the two-response-choice set and 248-264 ms for the four-response choice set). Further, when collapsed across response sets and congruency, the LRP for the Stroop task began earlier than the Flanker task (178 ms vs. $224 \mathrm{~ms}$, although for the Flanker task there was a brief period of significance from 164-182 ms before the main LRP component onset), suggesting more rapid onset of response preparation in the Stroop task, paralleling the faster RTs in that task. The LRP for the Stroop task significantly differed from that of the Flanker task (collapsed across response-choice set and congruency) from 186-438 $\mathrm{ms}$ and again from 502-538 ms. Of note, for each task and response-choice set, the LRP for the incongruent condition always onset somewhat later than the LRP for the congruent condition, again paralleling the behavioral RT pattern (see Table 4). The LRP frequently onset earlier (or around) the time of the $\mathrm{N}_{\mathrm{inc}}$ for a given condition (discussed further below).

\subsubsection{Summary of neural effects indexed by the ERPS}

Fig. 7 shows each of the significant time periods of activity for each of the effects as a function of task and number of response choices. Across tasks, increasing the number of response options increased the duration of the $\mathrm{N}_{\text {inc }}$, as well as the duration of the LRP. As this figure suggests, one finding of note is that the LRP actually onset prior to the $\mathrm{N}_{\text {inc }}$ particularly in the Stroop task. Statistically, this was confirmed through permutation tests run on

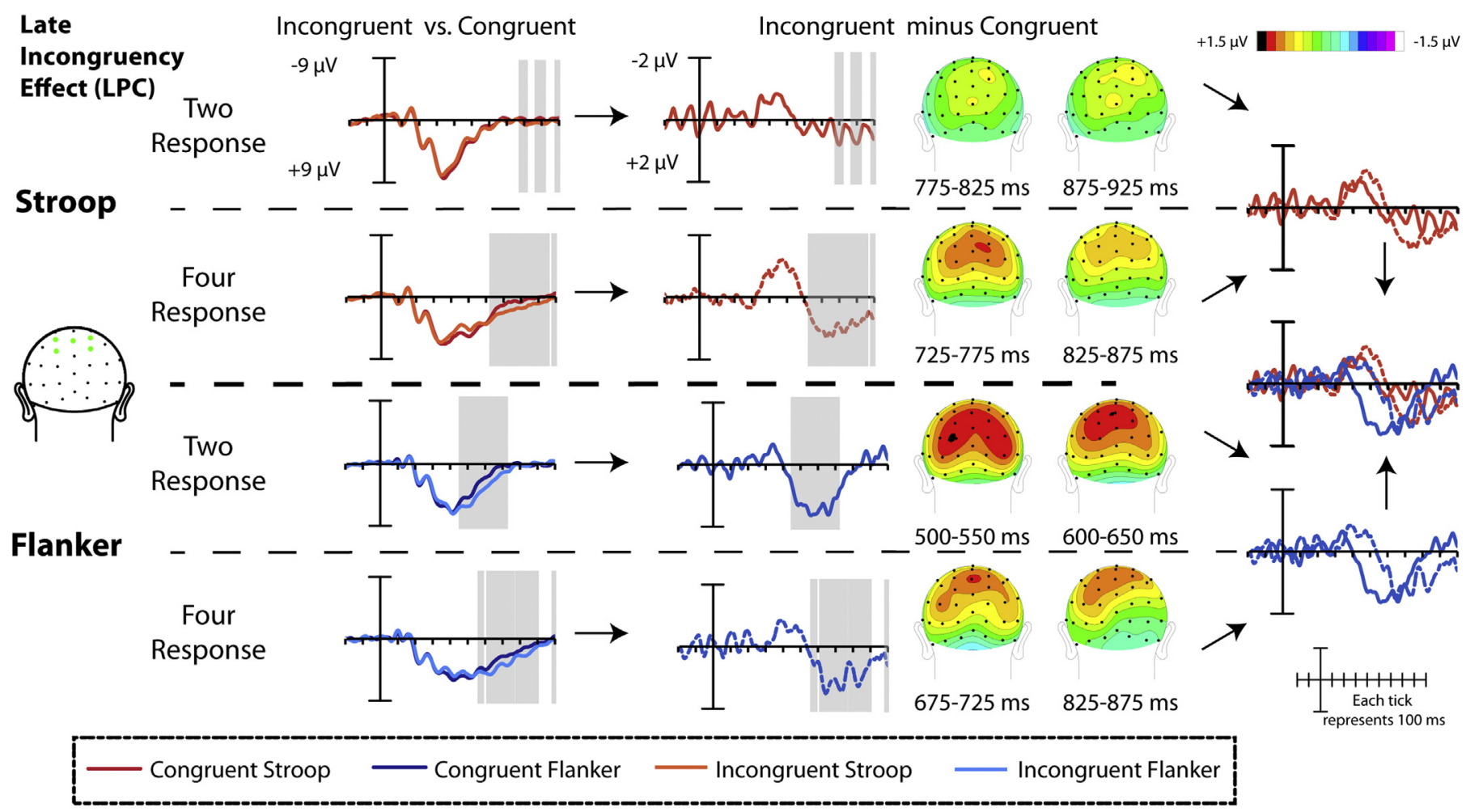

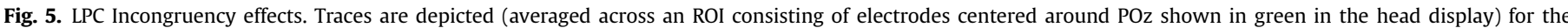

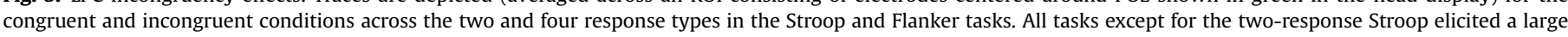

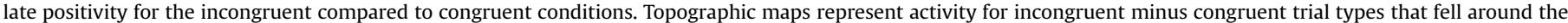
statistically significant time window for each respective condition. 


\section{Incongruent vs. Congruent | Two vs. Four | Stroop vs. Flanker}

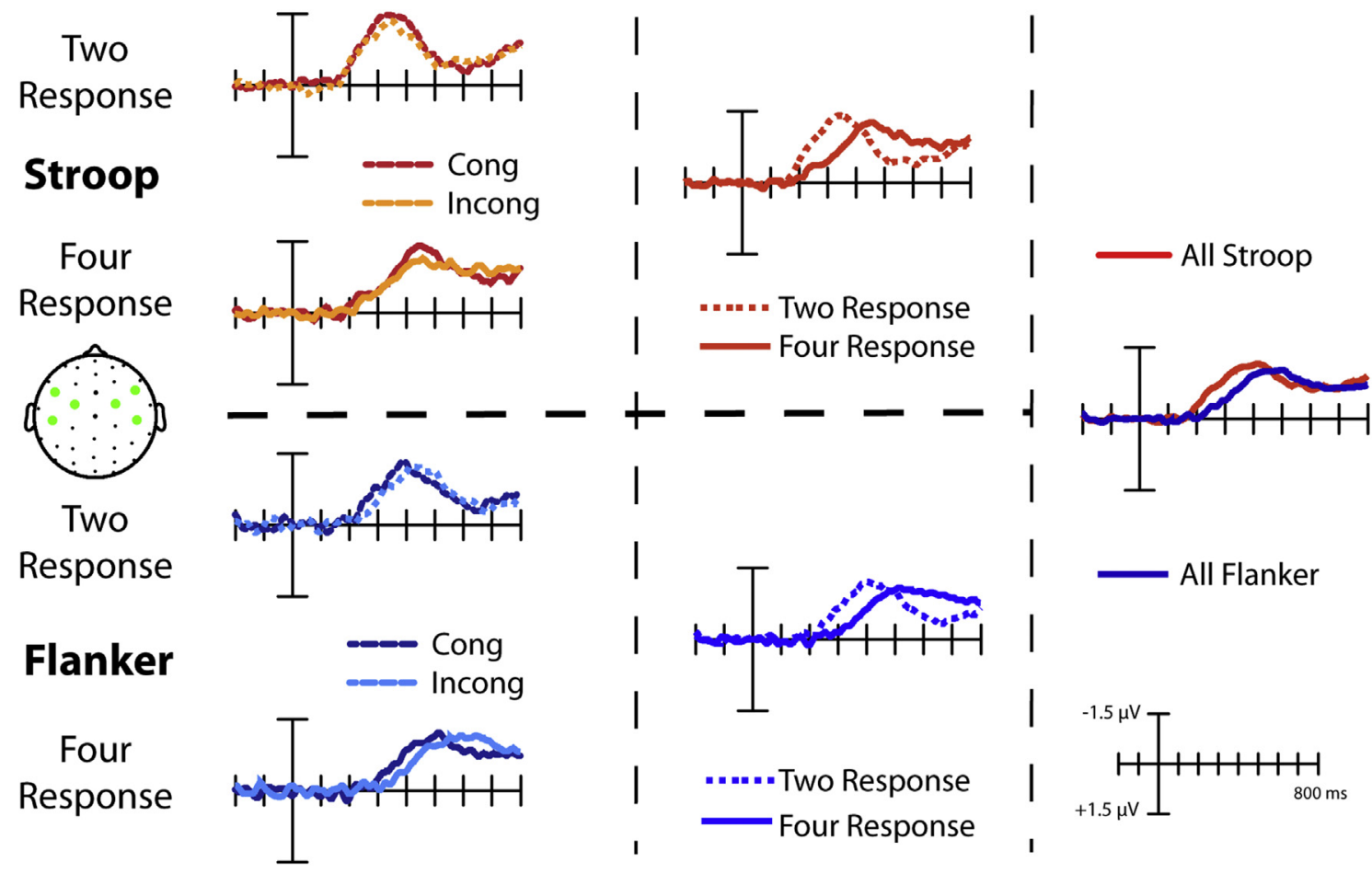

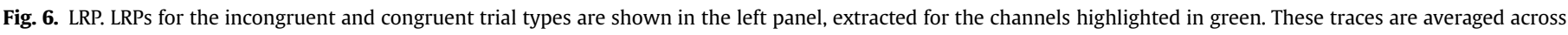

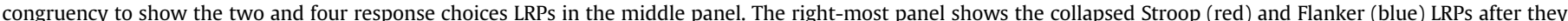

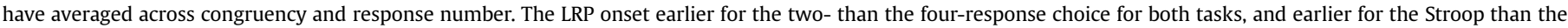
Flanker, mirroring the RT pattern.

Table 4

Onset of significant effects (in ms) for the LRP across conditions. Some conditions (e.g., the flanker two-response-choice congruent) showed a brief early period of significance before the substantial LRP effect. In all tasks and response configurations, the congruent condition onset before the incongruent condition, paralleling the behavioral data.

\begin{tabular}{lll}
\hline & Congruent & Incongurent \\
\hline Stroop Two-Response & $170-$ & $180-$ \\
Stroop Four-Response & $202-$ & $234-$ \\
Flanker Two-Response & $170-186,230-$ & $240-$ \\
Flanker Four-Response & $188-202,296-$ & $246-264,346-$ \\
\hline
\end{tabular}

the $\mathrm{N}_{\text {inc }}$ difference waves (i.e., incongruent minus congruent) vs, the LRP (with incongruent and congruent combined) for each response-choice and task. In the Stroop two-response-choice set, these two components differed from each other between 256 and $336 \mathrm{~ms}$. In the Stroop four-response choice set, these components differed from each other from 238-312 ms. In the Flanker tworesponse choice set, these components did not differ from each other; however in the Flanker four-response choice set, these components differed from each other from 176 to $208 \mathrm{~ms}$ and then again from $310-400 \mathrm{~ms}$.

\section{Discussion}

In the current study, we sought to map the time course of stimulus and response conflict processing across two different classic tasks for examining executive control, the Stroop and Flanker tasks. By also varying the number of response options, while maintaining the type and level of stimulus conflict constant, we were able to separate semantic and spatial conflict processes from each other and from response processes. In turn, we are then able to relate these to hallmark ERP components that index different neural functions in the same participants. From this, we observed several electrophysiological patterns that unfolded along the temporal cascade of conflict detection and resolution. First, spatial conflict evoked an early, frontally-distributed component that was not significantly present for the semantic conflict. Second, response preparation started prior to the first (detectable) incongruency-related difference in the case of semantic conflict. Third, the size of the response set had an effect on the duration of the incongruency-related $\mathrm{N}_{\text {inc }}$, with increased set size producing a $\mathrm{N}_{\text {inc }}$ of longer duration. Moreover, semantic conflict elicited a longer $\mathrm{N}_{\text {inc }}$ than spatial conflict, although this component onset slightly earlier for the case of spatial conflict. Fourth, the LPC, which onset around the time of the behavioral response, was strongly present across most tasks and response conditions, with the exception of the two-response choice Stroop conflict, which also showed the smallest amount of behavioral conflict. Fifth, the neural activity reflecting motor-preparation processes (the LRP) onset as early as, or even earlier than, these incongruency-related effects, suggesting incongruency-related neural processing and motor preparation do not occur sequentially but rather simultaneously. Together, these results suggest a multifaceted pattern of executive function that employs several interacting subsystems, with multiple processes operating in a parallel, rather than serial manner, and stimulus-related conflict and response-related conflict having unique influences on the patterns of cognitive control processes.

\subsection{Behavioral effects}

Behaviorally, all tasks and response-choice options elicited a behavioral incongruency effect, with significantly slower RTs and lower accuracy on incongruent trials relative to congruent trials, in line 
Stroop

Incongruency-Related

Activity (Incong minus

Cong)

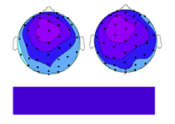

Two Response
Flanker

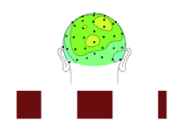

I
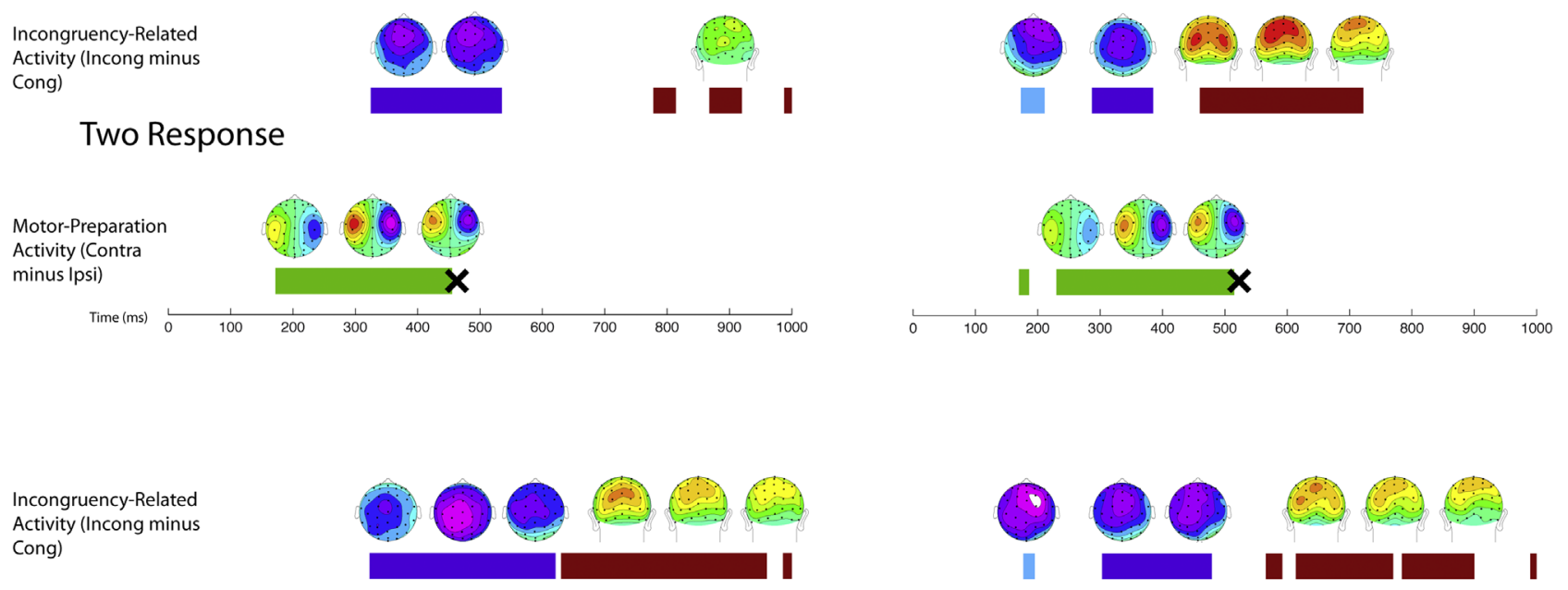

\section{Four Response}
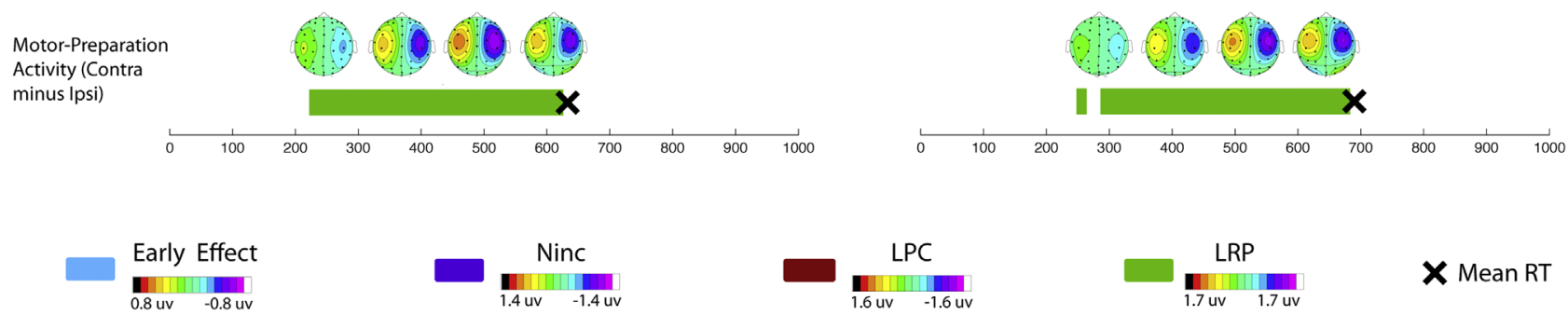

X Mean RT

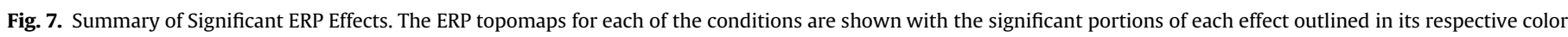

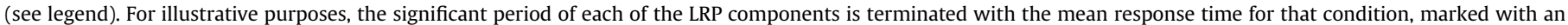
' $\mathrm{X}$ ', although the component appeared to last longer than the mean RT.

with previous findings of behavioral incongruency effects observed in both Stroop (e.g., MacCleod, 1991; Klopfer, 1996) and Flanker (e.g., Bunge, Hazeltine, Scanlon, Rosen, \& Gabrieli, 2002; Kopp, Rist, \& Mattler, 1996; Miller, 1991) conflict tasks. These incongruency effects were modulated by the number of response choices, with larger effect sizes in the four-choice conditions relative to the two-choice conditions for both tasks. Adding more response options slowed down the RTs and decreased accuracy, likely due to the need for a more complex response-selection process that had to arbitrate over more response choices (Broadbent \& Gregory, 1965; La Heij \& van den Hof, 1995). Participants were faster and more accurate on the Stroop compared to the Flanker task, which would tend to suggest that semantic conflict is more readily resolved than spatial conflict, at least with the stimulus configurations employed here. This could be the result of the relative physical sizes of the relevant information between the two tasks used here, however, as the Stroop task had a box full of color compared to a single letter in the Flanker task to which the participant must attend. With more relevant information physically present in the Stroop task, this may have contributed to the improved accuracy and RTs as we see here.

\subsection{Neural processing effects}

\subsubsection{Early incongruency effect}

The first significant neural difference between incongruent and congruent trial types was only present in the Flanker task, appearing as an anteriorally-distributed negativity at around $200 \mathrm{~ms}$ post-stimulus. This effect was present for both the two and fourresponse set conditions, lasting slightly longer in the two-response choice condition. The presence of this effect in the Flanker task and its absence in the Stroop task suggests that it may be specifically related to the spatial-conflict detection. As the Flanker task presents a specific match/mismatch between the central stimulus and surrounding stimulus, this early effect may reflect the initial detection of the spatial mismatch. Given that low-level features of shape, such as orientation, is processed in early visual cortex (Haynes \& Rees, 2005), it is indeed possible that by $200 \mathrm{~ms}$ differences between the processing of congruent and incongruent configurations would be observed neurally. The majority of EEG studies using the Flanker task have not reported effects this early (e.g., Bartholow et al., 2005; Beste et al., 2008; Brydges et al., 2012; Danielmeier et al., 2009; Freitas et al., 2009; Frühholz et al., 2011; Tillman \& Wiens, 2011; Wendt et al., 2007; Yeung, Botvinick, \& Cohen, 2004); however, it could be the case that with other stimulus configurations this early effect may not be distinguishable in time from (e.g., may merge with) the later incongruency-related negativity (e.g., the $\mathrm{N} 2 / \mathrm{N}_{\text {inc }}$ ) that has been reported in these studies (see Folstein \& Van Petten, 2008). Previous work from our group (Appelbaum et al., 2011) found that the incongruency-related negativity for the Flanker task lasted from approximately $150-450 \mathrm{~ms}$, suggesting that perhaps both this early negativity and the later $\mathrm{N}_{\text {inc }}$ can merge and become indistinguishable across this time period.

Of note, although this effect was not statistically present in the Stroop task, the incongruency difference waves for the Stroop task in Fig. 3 show a slight hint of this component. In our study, the version of Stroop task that was used was slightly different from that of a more traditional Stroop task, in that the stimulus components (the color and the word) were spatially separate from each other. Perhaps this spatial separation between the two facets of the stimulus created a bit of spatial conflict as well, thereby possibly causing the small but non-significant deflection at this 
latency. As this early N2 effect has not previously been reported for Stroop tasks, it may indeed be something unique to the design of our stimulus, and perhaps if there had been an even greater spatial aspect involved in the stimuli, this could have made this N2 larger and statistically present. Importantly, however, our Stroop stimulus still resulted in the traditional incongruency effects and components that have been previously observed for Stroop tasks that have used colored words for stimuli (e.g., Liotti et al., 2000), indicating that our task is indeed eliciting the semantic-based Stroop conflict..

\subsubsection{Intermediate-latency incongruency effect $\left(N_{i n c}\right)$}

The second neural incongruency effect in the Flanker task, and the first in the Stroop, was the more centrally distributed, incongruency-related negativity $\left(\mathrm{N}_{\mathrm{inc}}\right)$. This effect was present for all tasks and response conditions, although it onset at slightly different times for the two tasks, starting earlier in the Flanker task than in the Stroop task by about $40 \mathrm{~ms}$, but lasting longer in the Stroop task by over $100 \mathrm{~ms}$ on average. Another robust difference between conditions, however, was in the duration of this effect as a function of response choice set. Specifically, for both the Stroop and the Flanker tasks, this effect lasted approximately $100 \mathrm{~ms}$ longer in the four-response choice conditions than in the tworesponse choice conditions, albeit most robustly statistically confirmed in the Flanker task. The ability to directly compare both stimulus and response conflict here demonstrates that, although the $\mathrm{N}_{\text {inc }}$ is somewhat influenced by the type of conflict present, it is particularly sensitive to the number of response options, with more response choices leading to prolonged conflict-related activity. As such, instead of referring to the N450 effects for the Stroop task, and the N2 for the Flanker, we believe the $\mathrm{N}_{\text {inc }}$ encompasses these previously reported effects, now directly compared across tasks.

The timing of this negativity observed in our Flanker task is slightly later than that which is often reported for Flanker tasks, where the negativity typically being observed to onset as early 220 ms (Tillman \& Wiens, 2011) and peaking at around $300 \mathrm{~ms}$ (e.g., Bartholow et al., 2005; Beste et al., 2008; Danielmeier et al., 2009; Freitas et al., 2009). Although some Flanker-task studies use arrow stimuli (pointing up/down or left/right typically) instead of letters, which may elicit a more rapid, automatic processing (Eimer, 1995), there have nevertheless been studies that have used letters and found the incongruency effects still emerging quite early (e.g., Appelbaum et al., 2011; Bartholow et al., 2005; Wendt et al., 2007). Indeed, as mentioned above, this could be result of the blending of the two early negative incongruency effects observed here, or it could have to do with aspects that are stimulus specific, such as where in the visual field the stimuli lay, how large the targets and flankers were, or other minor differences in experimental parameters. Importantly, however, by directly comparing the Stroop and Flanker tasks within subjects, the present data suggest that the $\mathrm{N} 2$ and $\mathrm{N} 450 / \mathrm{N}_{\text {inc }}$ are likely reflecting similar conflict-related processes, as this component was most substantially modulated by the number of response options present, whereas it had only minor variations in timing as a function of task.

Given that source modeling of this conflict-related negativity has suggested that it originates, at least in part, from the anterior cingulate cortex (ACC) in both the Stroop (Liotti et al., 2000) and Flanker tasks (van Veen \& Carter, 2002b), we infer that the function of this region is primarily related to response conflict, as supported both by its substantial modulation of duration by response number, as well as other evidence described below. However, as the duration of activity can also be modulated by the nature of the conflict, it is not surprising that results from other studies have been somewhat mixed. In line with the current findings, several other experiments using fMRI and the Stroop task showed that although a small region of the ACC was activated by stimulus conflict, a much greater region was activated under conditions of response conflict (Milham, Banich, \& Barad, 2003; van Veen \& Carter, 2005). Several other fMRI studies using the Stroop task have shown that ACC activation was entirely dependent on response conflict (Milham et al., 2001; Zysset, Müller, Lohmann, \& Cramon, 2001). Likewise, in the Flanker task, the activation of the ACC has also been show to be sensitive to response conflict (van Veen, Cohen, Botvinick, Stenger, \& Carter, 2001). Nevertheless, Weissman et al. (2003), showed robust dACC activity in a global/local conflict task for both stimulus conflict and response conflict, suggesting that under certain circumstances the ACC can be involved in processing both types of conflict.

Within the electrophysiological literature on conflict processing, the pattern of findings as to the role of the N450/N2 in stimulus vs. response conflict is also mixed. In a study using a counting Stroop task, the N450 was shown to be sensitive to conflict that came from both the stimulus level and from the response level (West, Bowry, \& McConville, 2004), or just from the stimulus level (Szúcs \& Soltész, 2012). In a semantic version of the Stroop task (Killikelly \& Szúcs, 2013), the N450 was modulated by both stimulus and response conflict. In an EEG study of the Flanker task, no differences between stimulus conflict and response conflict were observed (Wendt et al., 2007); however, a different EEG study did observe an enhanced N2 for response conflict (van Veen \& Carter, 2002b). Our electrophysiological findings, therefore, seem to be most consistent with the results from the fMRI literature suggesting that a portion of the ACC may be involved in stimulus conflict processing, but the main function of this region is in dealing with response conflict.

One further point of note is that the longer duration of the $\mathrm{N}_{\text {inc }}$ for the four-response-choice condition over the two-responsechoice condition was statistically confirmed in the Flanker task, with the differences in these responses for the Stroop task being only briefly statistically longer. This difference between the $\mathrm{N}_{\text {inc }}$ for the tasks could be caused by a few different factors. First, as the Stroop task was overall somewhat easier (i.e., faster RTs), it is possible that the response-conflict manipulation had less of an impact in that task as compared to the more difficult Flanker task. Another possibility is that both spatial conflict and response conflict both involve an aspect of spatial mapping, and as such, when the spatial mapping becomes more complex for the responses, it interacts more with the stimulus conflict, causing a prolonged $\mathrm{N}_{\text {inc }}$. Regardless of the cause, our data do suggest that there was more response conflict elicited in the response choice manipulation in the Flanker task, showing how the type of conflict can interact with the response options.

Another interesting pattern of results observed here is how the $\mathrm{N}_{\text {inc }}$ may be related to behavior. Specifically, this component onset earlier in the instances of spatial conflict as compared to semantic conflict, lasted longer for semantic conflict, and yet the response times in the spatial conflict task were somewhat longer. This pattern of results suggests a couple of possible functional roles that this component might reflect, with perhaps the most plausible being that it is not involved in conflict resolution per se. If it were involved in such resolution, then one would expect faster RTs for the Flanker task as this component both onset earlier and had a shorter duration. Accordingly, it seems more likely that this component is primarily involved in conflict detection, with the resolution entailing other processes, which ultimately enable output of the correct response. Of note, in the Stroop task with the four-response choice options, the $\mathrm{N}_{\text {inc }}$ amplitude correlated with the RT incongruency effect across subjects, with participants who had a larger RT difference between incongruent and congruent trial types also eliciting a larger $\mathrm{N}_{\text {inc }}$ neural incongruency effect. It is unclear as to why this task and response configuration was the 
only one in the present study to show this brain-behavioral relationship, particularly when some previous work has found such a correlation to also be present in the Flanker task (Appelbaum et al., 2011). The four-response choice Stroop task here was the task for which this component had the longest duration, so it could also be that this component had the most robust signal present, allowing for a statistically reliable correlation. Further work linking these electrophysiological effects directly to behavior would be important for more fully determining their relationships.

\subsubsection{Late conflict effect (LPC)}

The later conflict effect on the posterior LPC component was observed robustly in three out of the four task configurations. The fourth condition, the two-response choice Stroop task, showed small hints of this effect, but it did not last nearly as long as it did in the other tasks and was not as robust (see Figs. 4 and 6). This task was also the easiest task behaviorally, with the highest accuracy and shortest RTs overall. Importantly, this task still had incongruency effects, but it is possible that if the Stroop stimuli had been of the more traditional type, with the color in the font of the word itself instead of being a color patch around it, the effects may have been larger, and the task more difficult. It could be the case that this incongruency-related difference represents the allocation of attention, with more attention needed for the more difficult tasks. This would be in accordance with previous findings showing that this component is related to conflict adaption in a Stroop task, with a greater difference between incongruent and congruent trials being observed as a function of trial sequence (Donohue et al., 2012; Larson et al., 2009). More specifically, in both the Donohue et al. and Larson et al. studies, this component was observed with a greater magnitude in cases where attention would be ramped up on the next trial (i.e., when an incongruent trial followed a congruent trial), likely as a way of implementing a higher level of cognitive control.

The onset and duration of this late positive component appears to be independent of both the task (i.e., the type of stimulus conflict present), and the number of response choices, as it showed no clear pattern with respect to these task manipulations here. This component may instead be important in general conflict resolution, even after the behavioral response, as has been suggested by Coderre and colleagues (2011). In their study, they manipulated the onset of Stroop stimuli (color vs. semantic information) and found that the LPC was not present when the irrelevant information came $400 \mathrm{~ms}$ later. That is, by the time the conflicting information onset, the response selection was already accomplished, and thus the conflict did not need to be resolved. Indeed, it could be the case that here the lack of a substantial LPC in the case of the two-response Stroop task would indicate that the conflict had been resolved and/or that it was just particularly easy to resolve and did not require much of such processing.

\subsubsection{Motor-preparation-related processes (LRP)}

A specific measure of the onset of response preparation can be assessed from the motor-related LRP component. Here, we found that the LRP consistently onset later in time for the incongruent compared to congruent conditions, as well as for the four-response choice options compared to the two-response choice options. Further, the LRP lasted longer from onset to behavioral response in the four-response-choice compared to the two-response choice options. Thus, increasing the number of response options seems to increase the level of response conflict, thereby delaying response preparation in time and increasing it in duration. This is seen not only in the overall delay in the LRP onset, but specifically in the delay of the onset of the LRP for incongruent trials, which were substantially delayed relative to the congruent trials in the fourresponse choice set. Additionally, the LRP onset earlier in the
Stroop task than in the Flanker, which was not surprising given that the RTs were also faster in the Stroop task. These task-related LRP effects suggest it reflects how rapidly a participant was able to start a correct response, and, as this was faster for the Stroop task, it suggests that either the response-mapping in this task was more easily accessible, or that the stimulus conflict were more easily resolved and/or slightly less robust than in the Flanker task.

The LRP data provide a dissociation between actual motor preparation compared to the resolution of response conflict. That is, the $\mathrm{N}_{\mathrm{inc}}$, which appears to reflect the detection of response conflict, showed no relationship between its onset and the onset of the LRP. In the four-response-choice Flanker task, for example, the LRP and $\mathrm{N}_{\text {inc }}$ onset almost simultaneously, whereas in the other tasks the LRP onset before the $\mathrm{N}_{\text {inc. That is, in some cases it }}$ would appear that response preparation in the correct direction began, but then the actual behavioral output was delayed due to the detection of the conflict. Such a dissociation suggests that the detection and resolution of response conflict, the initiation of motor preparation, and the final motor output do not operate in a sequential manner, but that there is partial overlap of these functional processes, and a complex interplay between them. Accordingly, it is also important to note that the high temporal resolution of the EEG measures of neural processing employed in the present study was critical to being able to discern the temporal overlap and interplay of these processes, which would be difficult to capture in either behavioral or fMRI studies of conflict.

Across all of these tasks, one thing we were unable to examine in the present study is the relative effect of facilitation and interference, because, due to trial numbers, there was no neutral condition present. Such a condition has proved quite useful in various previous studies, as it can serve to further tease apart stimulusresponse compatibility effects by providing a condition that has an non-matching stimulus, but with the incongruent part of the stimulus being not part of the response set (e.g., Milham et al., 2001). Therefore, although we operationalized response conflict as deriving from the number of eligible options, a response-ineligible condition is indeed another way to examine this, and it would be of value in future studies to directly compare the roles of these various types of response conflict.

\subsubsection{A final note on the current tasks used}

As mentioned above, the Stroop task used here did not have the color information contained in the word, but rather in a color patch surrounding the word. We used this particular version so that it would be comparable to our previous work on the Stroop task, in which the SOA of the color/word information was varied (e.g., Appelbaum et al., 2009; 2012, 2014). Having the color information present just adjacent to the semantic information resulted in the elicitation of conflict-related effects both behaviorally and neurally in the current study, as we and others (Cordere et al. 2011) have previously found. Additionally, our Flanker task used letters and not arrows, so it cannot easily be directly compared to tasks that used arrows (e.g., Tillman \& Wiens, 2011). Our results, therefore, should be interpreted within the context of these tasks, with the activation patterns potentially differing as a function of task used. Indeed differences that may be a function of task can be observed when comparing our results to that of Tillman \& Weins (2011). Specifically, Tillman \& Wiens found slower RTs in their Flanker arrow task compared to their Stroop task (although they did not report these statistical comparisons within their behavioral data and their Flanker task had only two response choices and their Stroop task had four), whereas we found the opposite pattern. It is therefore likely that the complexity of the stimuli, as well as the response set, will ultimately shape the cascade of conflict detection and resolution as well as response preparation processes. 


\section{Summary and conclusions}

The present study directly compared the electrophysiological components elicited by semantic versus spatial conflict, and how each of these was modulated by the amount of response conflict due to response-set size. The data suggest that spatial conflict is the first type of conflict to be detected in the brain, although the task with such conflict had the slowest overall response times, suggesting that the early detection did not help to resolve the conflict more rapidly. The initial conflict detection was followed by a frontal-central negativity, the $\mathrm{N}_{\text {inc }}$, that was sensitive to the amount of response conflict present (longer duration with more response conflict), indicating the role of this component in detecting and/or addressing such conflict. In contrast, the longer-latency LPC incongruency effect seemed not to be sensitive to either stimulus conflict or response conflict per-se, but rather to the relative task difficulty and the amount of attention needed to correctly perform the task. The LRP data confirmed that both incongruency and response set size delayed the onset of the motor preparation for the correct response. Of particular note is that the motor preparation for the behavior response onset at or before the first electrophysiological detection of conflict, particularly in the case of semantic conflict, suggesting there is an ongoing set of interactions between processes related to behavioral response output and the processing of conflicting input. In addition, the onset of the motor preparation process was delayed for incongruent relative to congruent trial types, suggesting that the conflict present in the incongruent trials had been enough to delay the onset of response preparation, with such differential processes occurring at or even before the other differential incongruency-related ERP effects. Together, the present data suggest that the neural activations engaged in conflict processing tasks mainly reflect response-selection difficulties (due to incongruency or response-mapping complexity), and the control processes necessary to resolve such conflict.

\section{Acknowledgements}

This work was supported by NIH grants R01-NS-051048 and R01-MH060415 to M.G.W and by funding from Otto-von-Guericke University in Magdeburg. The authors thank Jennifer Hong, Heather Wallace, Orane Douglas and Christopher Mazis for assistance with data collection.

\section{Appendix A. Supporting information}

Supplementary data associated with this article can be found in the online version at 10.1016/j.neuropsychologia.2016.01.035.

\section{References}

Appelbaum, L.G., Boehler, C.N., Davis, L.A., Won, R.J., Woldorff, M.G., 2014. The Dynamics of Proactive and Reactive Cognitive Control Processes in the Human Brain. Journal of Cognitive Neuroscience 26 (5), 1021-1038. http://dx.doi.org/ 10.1016/S0926-6410(02)00212-4.

Appelbaum, L.G., Boehler, C.N., Won, R.J., Davis, L.A., Woldorff, M.G., 2012. Strategic allocation of attention reduces temporally predictable stimulus conflict. Journa of Cognitive Neuroscience 24 (9), 1834-1848.

Appelbaum, L.G., Meyerhoff, K.L., Woldorff, M.G., 2009. Priming and Backward Influences in the Human Brain: Processing Interactions during the Stroop Interference Effect. Cerebral Cortex 19 (11), 2508-2521. http://dx.doi.org/10.1093/ cercor/bhp036.

Appelbaum, L.G., Smith, D.V., Boehler, C.N., Chen, W.D., Woldorff, M.G., 2011. Rapid Modulation of Sensory Processing Induced by Stimulus Conflict. Journal of Cognitive Neuroscience, 1-9. http://dx.doi.org/10.1162/jocn.2010.21575.

Appelbaum, L.G., Wade, A.R., Vildavski, V.Y., Pettet, M.W., Norcia, A.M., 2006. Cue-Invariant Networks for Figure and Background Processing in Human Visual Cortex. The Journal of Neuroscience: The Official Journal of the Society for Neuroscience 26 (45), 11695-11708. http://dx.doi.org/10.1523/JNEUROSCI.2741-06.2006.
Atkinson, C.M., Drysdale, K.A., Fulham, W.R., 2003. Event-related potentials to Stroop and reverse Stroop stimuli. International Journal of Psychophysiology 47 (1), 1-21.

Badzakova-Trajkov, G., Barnett, K.J., Waldie, K.E., Kirk, I.J., 2009. An ERP investigation of the Stroop task: The role of the cingulate in attentional allocation and conflict resolution. Brain Research 1253 (C), 139-148. http://dx.doi.org/10.1016/ j.brainres.2008.11.069.

Bartholow, B.D., Pearson, M.A., Dickter, C.L., Sher, K.J., Fabiani, M., Gratton, G., 2005. Strategic control and medial frontal negativity: Beyond errors and response conflict. Psychophysiology 42 (1), 33-42. http://dx.doi.org/10.1111/ j.1469-8986.2005.00258.x.

Beste, C., Saft, C., Andrich, J., Gold, R., Falkenstein, M., 2008. Stimulus-Response Compatibility in Huntington's Disease: A Cognitive-Neurophysiological Analysis. Journal of Neurophysiology 99 (3), 1213-1223. http://dx.doi.org/10.1152/ jn.01152.2007.

Botvinick, M.M., Braver, T.S., Barch, D.M., Carter, C.S., Cohen, J.D., 2001. Conflict monitoring and cognitive control. Psychological Review 108 (3), 624.

Broadbent, D.E., Gregory, M., 1965. On the interaction of S-R compatibility with other variables affecting reaction time. British Journal of Psychology 56 (1), 61-67.

Brydges, C.R., Clunies-Ross, K., Clohessy, M., Lo, Z.L., Nguyen, A., Rousset, C., et al., 2012. Dissociable Components of Cognitive Control: An Event-Related Potential (ERP) Study of Response Inhibition and Interference Suppression. PLoS One 7 (3), e34482. http://dx.doi.org/10.1371/journal.pone.0034482.t001.

Bunge, S.A., Hazeltine, E., Scanlon, M.D., Rosen, A.C., Gabrieli, J.D.E., 2002. Dissociable Contributions of Prefrontal and Parietal Cortices to Response Selection. Neuroimage 17 (3), 1562-1571. http://dx.doi.org/10.1006/nimg.2002.1252.

Caldas, A.L., Machado-Pinheiro, W., Souza, L.B., Motta-Ribeiro, G.C., David, I.A., 2012 The Stroop matching task presents conflict at both the response and nonresponse levels: An event-related potential and electromyography study. Psychophysiology 49 (9), 1215-1224. http://dx.doi.org/10.1111/ j.1469-8986.2012.01407.x.

Coderre, E., Conklin, K., van Heuven, W.J.B., 2011. Electrophysiological measures of conflict detection and resolution in the Stroop task. Brain Research, 1-9. http: //dx.doi.org/10.1016/j.brainres.2011.07.017.

Cohen, J.D., Dunbar, K., McClelland, J.L., 1990. On the control of automatic processes: a parallel distributed processing account of the Stroop effect. Psychological Review 97 (3), 332-361.

Coles, M.G.H. (1989). Modern mind-brain reading: Psychophysiology, physiology, and cognition.Psychophysiology, 26, 251- 269.

Danielmeier, C., Wessel, J.R., Steinhauser, M., Ullsperger, M., 2009. Modulation of the error-related negativity by response conflict. Psychophysiology 46 (6), 1288-1298. http://dx.doi.org/10.1111/j.1469-8986.2009.00860.x.

Delorme, A., Makeig, S., 2004. EEGLAB: an open source toolbox for analysis of single-trial EEG dynamics including independent component analysis. Journal of Neuroscience Methods 134 (1), 9-21. http://dx.doi.org/10.1016/j. jneumeth.2003.10.009.

Donohue, S.E., Liotti, M., Perez, R., Woldorff, M.G., 2012. Is conflict monitoring supramodal? Spatiotemporal dynamics of cognitive control processes in an auditory Stroop task. Cognitive, Affective, \& Behavioral Neuroscience 12 (1), 1-15. http://dx.doi.org/10.3758/s13415-011-0060-〈z .

Egner, T., 2007. Congruency sequence effects and cognitive control. Cognitive, Affective, \& Behavioral Neuroscience 7 (4), 380-390.

Eimer, M., 1995. Stimulus-response compatibility and automatic response activation: evidence from psychophysiological studies. Journal of Experimental Psychology: Human Perception and Performance 21 (4), 837-854.

Eriksen, B.A., Eriksen, C.W., 1974. Effects of noise letters upon the identification of a target letter in a nonsearch task. Perception \& Psychophysics 16 (1), 143-149.

Eriksen, C.W., Schultz, D.W., 1979. Information processing in visual search: A continuous flow conception and experimental results. Perception \& Psychophysics 25 (4), 249-263.

Fan, J., Flombaum, J.I., McCandiss, B.D., Thomas, K.M., Posner, M., 2003. Cognitive and Brain Consequences of Conflict. Neuroimage 18, 42-57.

Folstein, J.R., Van Petten, C., 2008. Influence of cognitive control and mismatch on the N2 component of the ERP: a review. Psychophysiology 45 (1), 152-170. http://dx.doi.org/10.1111/j.1469-8986.2007.00602.x.

Freitas, A.L., Banai, R., Clark, S.L., 2009. When cognitive control is calibrated: Eventrelated potential correlates of adapting to information-processing conflict despite erroneous response preparation. Psychophysiology 46 (6), 1226-1233. http://dx.doi.org/10.1111/j.1469-8986.2009.00864.x.

Frühholz, S., Ben Godde, Finke, M., Herrmann, M., 2011. Spatio-temporal brain dynamics in a combined stimulus-stimulus and stimulus-response conflict task. Neuroimage 54 (1), 622-634. http://dx.doi.org/10.1016/j. neuroimage.2010.07.071.

Gratton, G., Coles, M. G., Sirevaag, E. J., Eriksen, C. W., \& Donchin, E. (1988). Pre- and poststimulus activation of response channels: A psychophysiological analysis. Journal of Experimental Psychology: Human Perception and Performance, 14, 331-344.

Groppe, D.M., Urbach, T.P., Kutas, M., 2011. Mass univariate analysis of event-related brain potentials/fields I: a critical tutorial review. Psychophysiology 48 (12), $1711-1725$.

Hanslmayr, S., Pastötter, B., Bäuml, K.-H., Gruber, S., Wimber, M., Klimesch, W. 2008. The electrophysiological dynamics of interference during the Stroop task. Journal of Cognitive Neuroscience 20 (2), 215-225. http://dx.doi.org/10.1162/ jocn.2008.20020.

Haynes, J.-D., Rees, G., 2005. Predicting the orientation of invisible stimuli from activity in human primary visual cortex. Nature Neuroscience 8 (5), 686-691. 
http://dx.doi.org/10.1038/nn1445.

Huster, R.J., Wolters, C., Wollbrink, A., Schweiger, E., Wittling, W., Pantev, C., Junghofer, M., 2009. Effects of anterior cingulate fissurization on cognitive control during stroop interference. Human Brain Mapping 30 (4), 1279-1289. http://dx. doi.org/10.1002/hbm.20594.

Kahneman, D., Chajczyk, D., 1983. Tests of the automaticity of reading: dilution of Stroop effects by color-irrelevant stimuli. Journal of Experimental Psychology: Human Perception and Performance 9 (4), 497-509.

Keele, S.W., 1972. Attention Demands of Memory Retrieval. Journal of Experimental Psychology 93 (2), 245-\&.

Killikelly, C., Szúcs, D., 2013. Asymmetry in stimulus and response conflict processingacross the adult lifespan: ERP and EMG evidence. Cortex; a Journal Devoted to the Study of the Nervous System and Behavior, 1-16. http://dx.doi. org/10.1016/j.cortex.2013.08.017.

Klein, G.S., 1964. Semantic power measured through the interference of words with color-naming. The American Journal of Psychology 77, 576-588.

Klopfer, D.S., 1996. Stroop interference and color-word similarity. Psychological Science 7 (3), 150-157.

Kopp, B., Rist, F., Mattler, U., 1996. N200 in the flanker task as a neurobehavioral tool for investigating executive control. Psychophysiology 33 (3), 282-294.

La Heij, W., 1988. Components of Stroop-like interference in picture naming. Memory and Cognition 16 (5), 400-410.

La Heij, W., van den Hof, E., 1995. Picture-word interference increases with targetset size. Psychological Research PRPF 58 (2), 119-133.

Lansbergen, M. M., \& Kenemans, J. L. (2008). Stroop interference and the timing of selective response activation. Clinical Neurophysiology, 119, 2247-2254.

Larson, M.J., Clayson, P.E., Clawson, A., 2014. International Journal of Psychophysiology. International Journal of Psychophysiology 93 (3), 1-15. http://dx.doi. org/10.1016/j.ijpsycho.2014.06.007.

Larson, M.J., Kaufman, D.A.S., Perlstein, W.M., 2009. Neural time course of conflict adaptation effects on the Stroop task. Neuropsychologia 47 (3), 663-670. http: //dx.doi.org/10.1016/j.neuropsychologia.2008.11.013.

Leuthold, H., Sommer, W. Ulrich, R. (2004). Preparing for action: inferences from CNV and LRP. Journal of Psychophysiology, 18, 77-88.

Liotti, M., Woldorff, M.G., Perez, R., Mayberg, H.S., 2000. An ERP study of the temporal course of the Stroop color-word interference effect. Neuropsychologia 38 (5), 701-711.

Lopez-Calderon, J., Luck, S.J., 2014. ERPLAB: an open-source toolbox for the analysis of event-related potentials. Frontiers in Human Neuroscience 8 , 213. http://dx. doi.org/10.3389/fnhum.2014.00213.

MacLeod, C.M., 1991. Half a century of research on the Stroop effect: an integrative review. Psychological Bulletin 109 (2), 163-203.

Markela-Lerenc, J., Ille, N., Kaiser, S., Fiedler, P., Mundt, C., Weisbrod, M., 2004. Prefrontal-cingulate activation during executive control: which comes first? Cognitive Brain Research 18 (3), 278-287. http://dx.doi.org/10.1016/j. cogbrainres.2003.10.013.

Milham, M.P., Banich, M.T., Barad, V., 2003. Competition for priority in processing increases prefrontal cortex's involvement in top-down control: an event-related fMRI study of the stroop task. Cognitive Brain Research 17 (2), 212-222. http://dx.doi.org/10.1016/S0926-6410(03)00108-3.

Milham, M.P., Banich, M.T., Webb, A., Barad, V., Cohen, N.J., Wszalek, T., Kramer, A.F., 2001. The relative involvement of anterior cingulate and prefrontal cortex in attentional control depends on nature of conflict. Brain Research. Cognitive Brain Research 12 (3), 467-473.

Miller, J., 1991. Channel interaction and the redundant-targets effect in bimodal divided attention. Journal of Experimental Psychology: Human Perception and Performance 17 (1), 160-169.

Nichols, T.E., Holmes, A.P., 2002. Nonparametric permutation tests for functional neuroimaging: a primer with examples. Human Brain Mapping 15 (1), 1-25.

Praamstra, P., Meyer, A. S., Cools, A. R., Horstink, M. W. I. M, \& Stegeman, D. F. (1996). Movement preparation in Parkin- son's disease: Time course and distribution of movement- related potentials in a movement precueing task. Brain, 119, 1689-1704.
Ridderinkhof, K.R., \& Van der Molen, M.W. (1995). A psychophysiological analysis of developmental differences in the ability to resist interference. Child Development, 66 (4) 1040-1056.

Schoenfeld, M.A., Tempelmann, C., Martinez, A., Hopf, J.M., Sattler, C., Heinze, H.J., Hillyard, S.A., 2003. Proceedings of the National Academy of Sciences 100 (20), 11806-11811.

Silton, R.L., Heller, W., Towers, D.N., Engels, A.S., Spielberg, J.M., Edgar, J.C., et al., 2010. The time course of activity in dorsolateral prefrontal cortex and anterior cingulate cortex during top-down attentional control. Neuroimage 50 (3), 1292-1302. http://dx.doi.org/10.1016/j.neuroimage.2009.12.061.

Stroop, J.R., 1935. Studies of interference in serial verbal reactions. Journal of Experimental Psychology: General 18, 643-662.

Szúcs, D., Soltész, F., 2012. Functional definition of the N450 event-relatedbrain potential marker of conflict processing: a numerical Stroop study. BMC Neuroscience 13 (1), 35. http://dx.doi.org/10.1186/1471-2202-13-35.

Tillman, C.M., Wiens, S., 2011. Behavioral and ERP indices of response conflict in Stroop and flanker tasks. Psychophysiology 48 (10), 1405-1411. http://dx.doi. org/10.1111/j.1469-8986.2011.01203.x.

van Veen, V., Carter, C.S., 2002a. The anterior cingulate as a conflict monitor: fMRI and ERP studies. Physiology \& Behavior 77 (4-5), 477-482.

van Veen, V., Carter, C.S., 2002b. The timing of action-monitoring processes in the anterior cingulate cortex. Journal of Cognitive Neuroscience 14 (4), 593-602. http://dx.doi.org/10.1162/08989290260045837.

van Veen, V., Carter, C.S., 2005. Separating semantic conflict and response conflict in the Stroop task: A functional MRI study. Neuroimage 27 (3), 497-504. http: //dx.doi.org/10.1016/j.neuroimage.2005.04.042.

van Veen, V., Cohen, J.D., Botvinick, M.M., Stenger, V.A., Carter, C.S., 2001. Anterior Cingulate Cortex, Conflict Monitoring, and Levels of Processing. Neuroimage 14 (6), 1302-1308. http://dx.doi.org/10.1006/nimg.2001.0923.

Weissman, D.H., Giesbrecht, B., Song, A.W., Mangun, G.R., Woldorff, M.G., 2003. Conflict monitoring in the human anterior cingulate cortex during selective attention to global and local object features. Neuroimage 19 (4), 1361-1368. http://dx.doi.org/10.1016/S1053-8119(03)00167-8.

Wendt, M., Heldmann, M., Münte, T.F., Kluwe, R.H., 2007. Disentangling sequential effects of stimulus-and response-related conflict and stimulus-response repetition using brain potentials. Journal of Cognitive Neuroscience 19 (7), 1104-1112.

West, R., Alain, C., 1999. Event-related neural activity associated with the Stroop task. Cognitive Brain Research 8 (2), 157-164.

West, R., Alain, C., 2000. Effects of task context and fluctuations of attention on neural activity supporting performance of the stroop task. Brain Research 873 (1), 102-111.

West, R., Bowry, R., McConville, C., 2004. Sensitivity of medial frontal cortex to response and nonresponse conflict. Psychophysiology 41 (5), 739-748. http: //dx.doi.org/10.1111/j.1469-8986.2004.00205.x.

Yeung, N., Botvinick, M.M., Cohen, J.D., 2004. The Neural Basis of Error Detection: Conflict Monitoring and the Error-Related Negativity. Psychological Review 111 (4), 931-959. http://dx.doi.org/10.1037/0033-295X.111.4.931.

Zhang, H.H., Zhang, J., Kornblum, S., 1999. A parallel distributed processing model of stimulus-stimulus and stimulus-response compatibility. Cognitive Psychology 38 (3), 386-432. http://dx.doi.org/10.1006/cogp.1998.0703.

Zhang, H., Kornblum, S., 1998. The effects of stimulus-response mapping and irrelevant stimulus-response and stimulus-stimulus overlap in four-choice Stroop tasks with single-carrier stimuli. Journal of Experimental Psychology: Human Perception and Performance 24 (1), 3-19.

Zysset, S., Müller, K., Lohmann, G., Cramon, von, D.Y., 2001. Color-Word Matching Stroop Task: Separating Interference and Response Conflict. Neuroimage 13 (1), 29-36. http://dx.doi.org/10.1006/nimg.2000.0665. 